\title{
Dinâmica da Renda Per Capita, Longevidade e Educação nos Municípios Brasileiros
}

\author{
- João Carlos Ramos Magalhães*
}

\author{
- ROGÉRIO BOUERI MIRANDA**
}

\begin{abstract}
RESUMO
Este trabalho analisa a dinâmica de distribuição da Renda Per Capita, da Taxa de Alfabetização, dos Anos de Estudo Concluídos e da Expectativa de Vida ao Nascer nos municípios brasileiros. A estimação de matrizes de transição revelou os padrões nacionais, regionais e intrarregionais de convergência no período entre 1970 e 2000. As várias mudanças na estrutura municipal brasileira demandaram o agrupamento dos municípios em Áreas Mínimas Comparáveis (AMC). As estimações revelaram dois resultados importantes: a) convergência para as variáveis ligadas à educação, mas convergência em clubes para a Renda Per Capita e Longevidade; b) o clube de baixa Renda Per Capita, formado pelas AMC do Norte e do Nordeste, apresentou apenas um terço da Renda Per Capita de longo prazo do clube de alta renda, formado pelas AMC do Sul, do Sudeste e do Centro-Oeste.
\end{abstract}

\section{Palavras-Chave}

desenvolvimento regional, clubes de convergência, dinâmica de distribuição, métodos não paramétricos

\begin{abstract}
This work analyses the dynamics of Per Capita Income, Literacy Rates, Years of Study and Life Expectation distributions on Brazilian municipalities. The estimation of transition matrices modeled the national, regional and intra-regional convergence pattern for the period from 1970 to 2000 . The many changes in the Brazilian municipality structure demanded the grouping of municipalities into Minimal Comparable Areas (MCA). The estimations revealed two important results: a) convergence for the variables related to education, but convergence in clubs for Longevity and Per Capita Income; b) the low Per Capita Income club, formed by the North and Northeast MCA, presented approximately one third of the long term Per Capita Income in the high income club, formed by the Center-West, South and Southeast.
\end{abstract}

\section{KEYWORDS}

regional development, convergency clubs, distribution dynamics, non-parametric methods

\section{JEL Classification}

$\mathrm{RII}, \mathrm{RI} 5$ e $\mathrm{Cl} 4$

\footnotetext{
* IPEA/DIRUR. Endereço para contato: SBS Quadra I, Bloco J, Ed. BNDES, Sala 3II, Brasília, DF. CEP: 70076-900. Email: joao.magalhaes@ipea.gov.br.

** Universidade Católica de Brasília e IPEA/DIRUR. Endereço para contato: SGAN 916, Módulo A, Sala AII3, Brasília DF. CEP: 70790-160. E-mail: rmiranda@ucb.br.

(Recebido em setembro de 2006. Aceito para publicação em dezembro de 2007).
} 


\section{$1 \quad$ INTRODUÇÃO}

Vários trabalhos têm sido realizados no Brasil para compreender e desenvolver políticas que reduzam as desigualdades econômicas e sociais existentes entre seus indivíduos e entre suas regiões, Estados e municípios. A permanência destas desigualdades contraria uma das principais previsóes da teoria neoclássica de crescimento econômico, proposta inicialmente por Solow (1956), Swan (1956), Ramsey (1928), Cass (1965) e Koopmans (1965): convergência ${ }^{1}$ da Renda Per Capita. Com base nesta teoria, esperase que a velocidade de convergência entre municípios e Estados de um mesmo país seja ainda maior que entre países dado que as barreiras à mobilidade do capital e da mão de obra são menores e os parâmetros comportamentais e tecnológicos são mais homogêneos.

A hipótese de convergência absoluta da Renda Per Capita entre os estados brasileiros não pode ser rejeitada estatisticamente pelos testes realizados em Ferreira e Diniz (1995) para o período entre 1970 e 1985. O trabalho de Azzoni (2001) confirma esse resultado para o período entre 1939 e 1996, mas obtém uma velocidade de convergência bem menor e adiciona que o processo de convergência cessou a partir de 1985.

Um resultado diverso foi obtido por Azzoni et al. (2004) a partir de microdados de 19 Estados brasileiros obtidos da Pesquisa Nacional por Amostra de Domicílios $(\text { Pnad })^{2}$, no período entre 1981 e 1996. Esse trabalho mostrou que as Rendas Per Capita convergem apenas em nível condicional e que a meia vida de convergência é menor que um ano, o que significa dizer que o processo de convergência está praticamente finalizado e que as atuais diferenças de renda permanecerão inalteradas em razão das diferenças educacionais e geográficas dos Estados estudados.

Testes realizados a partir de outra metodologia - estimações de matrizes de transição de Markov - também têm revelado não-convergência absoluta ou mesmo divergência absoluta da renda per capita. Ferreira (1998) mostrou que os PIBs per capita estaduais se concentraram em dois blocos entre 1970 e 1995. Pontual e Porto Júnior (2000) mostram uma estratificação da Renda Per Capita Estadual, entre 1985 e 1998, em três grupos: um grupo de estados pobres com 26,9\% dos Estados, o de renda média com $52 \%$ dos Estados e o terceiro de Estados ricos com 11,4\% dos estados. Já Mossi et al. (2003) mostraram elevada persistência das Rendas Per Capita, entre 1939 e 1998, em dois grandes grupos: o de baixas rendas formado principal-

1 Por convergência entende-se a tendência progressiva de queda no tempo das diferenças dos valores relativos da variável estudada entre as diferentes economias.

2 Existência de eletricidade, água, esgoto, coleta de lixo, fogão, geladeira, densidade dos domicílios, expectativa de vida, sexo, taxa de mortalidade infantil, temperatura, chuva, latitude, educação e participação do chefe e do cônjuge na renda familiar, e se a residência é metropolitana, urbana ou rural. 
mente pelos Estados da Região Nordeste e o de altas rendas formado pelos Estados das Regiões Sudeste e Sul. A estimação de núcleos estocásticos confirmou essa elevada persistência, tanto na análise incondicional quanto na condicionada espacialmente.

Distinguindo-se dos trabalhos acima pela utilização de dados municipais, Laurini e Andrade (2003) também obtém, por meio de metodologias não-paramétricas, a formação de dois clubes de convergência entre 1970 e 1996. Seus resultados são confirmados estatisticamente por testes de multimodalidade.

Gondim et al. (2007) encontraram evidência de dois clubes de convergência dos PIBr estaduais: um clube com baixos PIBr formado pelos Estados do Norte e Nordeste e o segundo por Estados do Sul, Sudeste e Centro-Oeste. A partir de dados municipais de Renda Per Capita de 1970 a 2000, esse trabalho também mostrou que o nível de escolaridade e a localização geográfica (sendo esta entendida pela proximidade a outras economias) são fatores importantes para a formação desses clubes, ao contrário das variáveis que representam o nível de integração ao comércio internacional e a desigualdade de renda.

Vreyer e Spielvogel (2005), com base em dados de PIB municipal de 1970 a 1996, verificaram que a persistência das desigualdades entre municípios e o aumento no agrupamento de localidades pobres na Região Nordeste devem-se à evidência revelada no mesmo artigo de um padrão de crescimento com dependência espacial positivo.

Kroth e Dias (2006) avaliaram o impacto do capital humano e do crédito bancário no crescimento econômico dos municípios brasileiros entre 1999 e 2003 por meio de estudo econométrico em painéis de dados dinâmicos. Essas variáveis mostraram-se significantes por meio de estimativas GMM (Generalized Method of Moments) que evitam a possibilidade de causalidade reversa. Seus resultados foram corroborados por testes de Hansen e de Arrelano-Bond.

Como parte das diferenças de Renda Per Capita entre os municípios se deve a diferenças de preço, que não podem ser corrigidas pois não existem índices de preço municipais, estas podem superestimar as diferenças de qualidade de vida e bem-estar entre os municípios. Para Becker et al. (2003) o estudo da dinâmica da Renda Cheia, que se define pela soma da Renda Per Capita (qualidade de vida) à Expectativa de Vida ao Nascer (quantidade de vida), torna-se então mais revelador que o da Renda Per Capita. Suas estimações, realizadas para uma amostra de 49 países entre 1965 e 1995, mostraram a divergência de Renda Per Capita, mas convergência de Renda Cheia. 
Soares (2007) mostra que a relação entre Renda Per Capita e esperança de vida nos municípios brasileiros se deslocou consistentemente entre 1970 e 2000 . Por meio de estimações em painel dinâmico o trabalho explica $71 \%$ do crescimento em expectativa de vida: $33 \%$ foi explicado pelo aumento da renda per capita, $16 \%$ pelo acesso a água tratada, $16 \%$ pela alfabetização e $6 \%$ pelo saneamento básico.

A Expectativa de Vida é uma variável econômica crucial ao desenvolvimento econômico pois influencia a decisão dos indivíduos quanto ao tempo que permanecerão estudando. Para Mincer (1974) os indivíduos decidem quantos anos estudarão ao comparar seu custo de oportunidade (os salários perdidos mais as taxas escolares) com seu benefício (o aumento no valor presente dos fluxos salariais que receberão até o fim de suas vidas). Um aumento na Expectativa de Vida, tudo o mais constante, eleva o valor presente dos fluxos salariais e, assim, o acúmulo de capital humano.

Hazan e Zoabi (2003) adicionam que a longevidade é um fator determinante na decisão dos pais entre investir em quantidade de filhos ou em qualidade (educação) e confirmam, com base em dados dos últimos quatro séculos, que esta interação é capaz de explicar a taxa de crescimento populacional, educacional e de renda de vários países desenvolvidos e em desenvolvimento. Nas simulações de Ferreira e Pessoa (2003), residentes de um país que vivem em média 65 anos terão $23 \%$ a menos de escolaridade, $26 \%$ a menos de capital físico e uma renda de longo prazo $28 \%$ menor que a de habitantes de outro país que vivem em média 75 anos.

O presente trabalho descreve a dinâmica das distribuições intermunicipais da "Renda per Capita", dos "Anos de Estudo Concluídos", da "Taxa de Alfabetização" e da "Expectativa de Vida ao Nascer" por meio da estimação de matrizes de transição de Markov, metodologia desenvolvida por Quah (1993b), com a base de dados municipais dos censos de 1970, 1980, 1991 e 2000.

Esta metodologia nos permite, além de testar a hipótese de convergência de cada variável, identificar a existência de um ou mais grupos de convergência e localizar territorialmente os municípios pertencentes a cada grupo de convergência. Uma das principais contribuições do artigo refere-se à caracterização da dinâmica regional e intrarregional das variáveis estudadas, que é apresentada mediante tabelas para o Brasil e para as regiões brasileiras. As estimações confirmam fortes mudanças na distribuição territorial das variáveis estudadas.

O texto está organizado em sete seções juntamente com esta introdução. A metodologia está descrita na seção 2 e a organização da base de dados na seção 3 . Os 
resultados são apresentados na seção 4 . Na seção 5 , foram sintetizadas as conclusões obtidas a partir das estimações realizadas.

\section{METODOLOGLA}

Um dos principais objetivos dos trabalhos empíricos de crescimento econômico tem sido examinar os determinantes do crescimento de longo prazo e checar se a Renda Per Capita, condicionada a esses determinantes, converge em direção a uma trajetória de crescimento de estado estacionário. A metodologia predominantemente utilizada nesses trabalhos consiste em regredir a taxa média de crescimento das economias estudadas contra o nível inicial de renda e as variáveis condicionantes estáticas, determinantes do crescimento, tais como: educação, investimentos, gastos públicos, circunstâncias políticas etc. ${ }^{3}$

Algumas suposições estão implícitas nessa metodologia: $i$ ) as variáveis condicionantes explicam o crescimento permanente ou a tendência de crescimento, enquanto a condição inicial é um controle para a dinâmica de transição; e ii) toda economia alcançará taxa de crescimento de estado estacionário, que pode ser aproximada por uma tendência temporal. Ao considerar-se que tal fato seja verdadeiro e que as economias estudadas estejam na trajetória de estado estacionário, pode-se estimar uma covariância estável no tempo entre a taxa média de crescimento e as variáveis hipotéticas explicativas do crescimento econômico.

Um dos problemas dessa metodologia é que ela sintetiza características dinâmicas em uma estatística resumida - uma média ou tendência de crescimento. Tal metodologia seria informativa caso os movimentos permanentes na renda fossem bem descritos por tendências temporais suaves, pouco afetadas por distúrbios correntes; ou, também, se grandes choques econômicos ocorressem apenas no começo da amostra. ${ }^{4}$ Quah (1993a) e Friedman (1992) alertam que também é inadequado supor que o coeficiente estimado é o mesmo para todas as economias e mostram que o coeficiente negativo encontrado em regressões de crescimento, entre a taxa de crescimento e a renda inicial, pode não significar convergência e sim sintoma de uma regressão à média, problema conhecido como Falácia de Galton.

Para evitar esses problemas, Quah (1993b) desenvolveu uma metodologia baseada em matrizes de mobilidade que modela a dinâmica das distribuições relativas de

3 Ver Barro (1991) e Barro e Sala-i-Martin (1991, 1992).

4 No entanto, Quah (1993b) mostra que esses cenários não descrevem dados de renda entre países: a tendência de crescimento de 78\% de 118 países, entre 1962 e 1973, foi maior que suas tendências de crescimento entre 1974 e 1985 , e a variabilidade na renda de $72 \%$ dessas economias aumentou significativamente no tempo. 
renda entre países como um processo de Markov. Entendemos essa metodologia como complementar à tradicional, pois não estima os determinantes do crescimento, mas testa a hipótese de convergência sem incorrer nas fraquezas estatísticas descritas acima e, ao formular uma lei de movimento para a distribuição da variável estudada entre os períodos em análise, permite capturar a existência de dois ou mais clubes de convergência.

\subsection{Matrizes de Mobilidade}

Suponha um painel de observações $\left\{x_{i t}\right\}$, onde $i=1,2, \ldots, n$ representa as unidades observacionais (municípios), e $t=1,2, \ldots, T$ refere-se aos períodos das observações. Para cada variável avaliada (Renda, Longevidade, Taxa de Alfabetização ou Anos de Estudo) será computada a média dos valores das unidades observacionais em cada período, $\bar{x}_{t}$ :

$$
\bar{x}_{t}=\sum_{i=1}^{n} x_{i t}
$$

Calcula-se, para cada período, a razão entre o valor da unidade observacional e o valor médio acima obtido $\left(\gamma_{i t}\right)$ :

$$
\gamma_{i t}=\frac{x_{i t}}{\bar{x}_{t}}
$$

Com base nos valores de $\gamma_{i t}$, separam-se as unidades observacionais de cada período em $k$ intervalos (ou classes). O passo seguinte é computar os deslocamentos dessas unidades entre os períodos de uma classe a outra. Essa contabilização gera a matriz de frequência $(F)$ :

$$
F=\left(\begin{array}{cccc}
f_{11} & f_{12} & \cdots & f_{1 k} \\
f_{21} & f_{22} & \cdots & f_{2 k} \\
\vdots & \vdots & \ddots & \vdots \\
f_{k 1} & f_{k 2} & \cdots & f_{k k}
\end{array}\right)
$$

na qual fij representa o número de municípios que pertenciam à classe $i$ em um período e migraram para a classe $j$ no período seguinte. Ao se dividir cada linha de $F$ por sua soma (o número de municípios pertencentes à linha $i$ ), obtém-se a matriz de transição $(P)$ : 


$$
P=\left(\begin{array}{cccc}
p_{11} & p_{12} & \cdots & p_{1 k} \\
p_{21} & p_{22} & \cdots & p_{2 k} \\
\vdots & \vdots & \ddots & \vdots \\
p_{k 1} & p_{k 2} & \cdots & p_{k k}
\end{array}\right)
$$

em que $p_{i j}=\frac{f_{i j}}{\sum_{m=1}^{k} f_{i m}}$ representa a probabilidade de um município que esteja na classe $i$ migrar para a classe $j$ no período seguinte.

\subsection{Distribuições Ergóticas}

A multiplicação do vetor $d$ (que representa a distribuição inicial das unidades observacionais em classes) pela matriz de transição $P$, resulta na distribuição esperada para o período seguinte, assim: $d_{t} P=d_{t+1}$

A aplicação iterativa desse processo possibilita que se estime a distribuição de um período futuro ( $s$ períodos no futuro, por exemplo). Assim:

$$
d_{t+s}=\underbrace{P \times P \times \ldots \times P}_{s \text { vezes }} \times d_{t}=P^{s} d_{t}
$$

em que $d_{t+s}$ é a distribuição esperada no período $t+s$. Se esse processo for levado ao limite, fazendo $s \rightarrow \infty$, pode-se averiguar se a distribuição resultante converge assintoticamente para alguma distribuição limite. Se tal convergência ocorrer, a distribuição final será denominada distribuição estacionária ou ergótica, que é aquela distribuição cuja pré-multiplicação pela matriz de transição resulta na própria distribuição, sendo portanto uma distribuição de equilíbrio, ponto fixo no qual o sistema se estabiliza. Matematicamente:

$$
\tilde{d} P=\tilde{d}
$$

O problema de se obter a distribuição $\widetilde{d}$ é correspondente ao de se achar o autovetor normalizado da matriz $P^{\prime}$, associado ao seu autovalor unitário, dada a existência do último:

$P^{\prime} x=\lambda x \Rightarrow P^{\prime} x=x$, visto que, nesse caso, $\lambda=1 \Rightarrow x^{\prime} P=x^{\prime}$, que é análoga à equação 7 , e onde $\lambda$ é o autovalor unitário e $x$ é o autovetor a ele associado. 
Como a matriz de transição possui todos os seus elementos não negativos e menores que 1 , pois trata-se de uma matriz de probabilidades, pode-se provar que pelo menos um dos seus autovalores é unitário. No entanto, se a matriz de transição possuir algum valor zero, não é possível assegurar a unicidade do autovalor desejado. Faz-se necessário então, no caso de trabalhos empíricos, testar o número de autovalores unitários associados a uma determinada matriz de transição. ${ }^{5}$ Isso porque a existência de mais de um autovalor unitário implica a existência de múltiplas distribuições ergóticas. Nesse caso, a distribuição final dependeria da distribuição inicial.

\subsection{Média e Variância das Distribuiçôes}

A média de cada distribuição é calculada multiplicando-se a frequência relativa de cada classe pelo seu valor cardinalizado. ${ }^{6}$ A seguir, somam-se tais produtos. Assim:

$$
\bar{x}=\sum_{m=1}^{k} m f_{m}
$$

A variância, por sua vez, é obtida pela soma ponderada dos quadrados dos desvios dos valores cardinais das faixas em relação à média da distribuição. As frequências relativas são os pesos a serem utilizados:

$$
s^{2}=\sum_{m=1}^{k}(m-\bar{x})^{2} f_{m}
$$

O cálculo das médias e das variâncias das distribuições visa estabelecer parâmetros de comparação entre estas últimas. No entanto, é imprescindível que fiquem claras as limitações desses parâmetros comparativos. Em primeiro lugar, deve-se notar que a média em questão refere-se às faixas e não aos valores. Assim, se todos os valores de uma determinada variável dobrarem, a média da distribuição permanecerá inalterada. Em seguida, é preciso ter em mente que variâncias menores não necessariamente significam melhoria na distribuição e sim podem ser produto, como por exemplo, de uma acumulação das unidades nas classes mais baixas.

\section{BASE DE DADOS}

A estrutura municipal brasileira sofreu muitas modificações entre os anos de 1970 e de 2000 em decorrência da emancipação de municípios, que elevou o número de mu-

5 Tal teste só é necessário no caso de a matriz de transição apresentar pelo menos um valor nulo.

6 Multiplica-se a frequência relativa da classe um por um, da classe dois por dois, e assim por diante. 
nicípios no Brasil de 3.952 em 1970 para 5.507 em 2000. Isso complica sobremaneira uma análise correta da evolução das variáveis de um dado município, uma vez que se deve levar em conta não só as alterações territoriais, mas também as populacionais provenientes das anexações e dos desmembramentos que alteraram sua estrutura.

Para que uma análise da evolução das características de um dado município possa ser feita, deve-se considerar essas alterações territoriais, utilizando-se unidades territoriais invariáveis, formadas pela reunião de municípios que juntos se envolveram em algum tipo de modificação territorial (anexação, desmembramento ou ambos).

O Instituto Nemesis (Ipea/RJ e Universidade Federal Fluminense - UFF) recompôs, a partir de informações do Instituto Brasileiro de Geografia e Estatística (IBGE), essas unidades territoriais em 3.659 Áreas Mínimas Comparáveis (AMC), as quais são definidas como as áreas geográficas mais desagregadas possíveis que podem ser comparadas entre dois pontos no tempo. ${ }^{7}$

Este trabalho analisa as dinâmicas da distribuição entre as AMC da Renda familiar Per Capita, na qual são consideradas todas as fontes de rendimento, sejam provenientes do trabalho ou não, da Taxa de Alfabetização (definida como o percentual das pessoas com 15 anos ou mais de idade que são capazes de ler ou de escrever um bilhete simples), do Número de Anos de Estudo Concluídos (que é a razão entre a soma do número de Anos de Estudo para a população de 25 anos ou mais de idade e o total das pessoas nesse segmento etário), e da Esperança de Vida ao Nascer (que corresponde ao número médio de anos que as pessoas viveriam a partir do nascimento).

As variáveis foram obtidas a partir dos Censos Geográficos do IBGE de 1970, 1980, 1991 e 2000 e posteriormente agregadas por AMC. É válido acrescentar que os dados do ano de 1970 estão disponíveis para 3.654 AMC e os de 1980 para 3.653 AMC. Nos anos de 1991 e de 2000, todas as 3.659 AMC tinham dados disponíveis.

\subsection{Aplicação das Matrizes de Mobilidade aos Dados}

Para cada ano foi calculada a média e todas as observações foram então divididas pela média do respectivo período.

7 Como exemplo, temos o município de Cruzeiro do Sul, no Estado do Acre. Seu território foi reduzido na década de 1970 devido à emancipação política de seu antigo distrito Mancio Lima. Em 1993, ele foi novamente reduzido pela criação dos Municípios de Marechal Thaumaturgo, Porto Water e Rodrigues Alves. Nesse caso, se houver interesse em analisar a evolução do PIB de Cruzeiro do Sul, entre 1970 e 2000, será necessário comparar o PIB de Cruzeiro do Sul em 1970 com a soma do PIB dos cincos municípios citados acima. Também existem casos, nos quais dois ou mais municípios distintos cedem partes dos seus territórios e de sua população para a formação de nova unidade municipal. 
Para evitar ao máximo a arbitrariedade envolvida na escolha dos limites das classes, para cada variável foram considerados os dados do primeiro ano (1970) e estes repartidos em nove classes com o mesmo número de unidades. Os limites obtidos foram aplicados na separação das classes nos demais períodos. Vale notar que este método, além de reduzir a discricionariedade da escolha das classes, ${ }^{8}$ permite que a tendência de convergência, não-convergência ou divergência regional das variáveis sejam mais bem apreciadas, posto que todas elas partem inicialmente de distribuições iguais.

Foram contabilizadas então todas as situações nas quais houve ou não mudança de classes de cada variável de um período para o outro a fim de que pudessem ser computadas as matrizes de frequência. A partir das matrizes de frequências foram calculadas as matrizes de transição. Cada matriz de transição foi então testada para se verificar a unicidade do autovalor unitário, após terem sido calculadas as distribuições ergóticas das diversas variáveis. Exercício semelhante foi realizado em escala intrarregional. Por fim, foram calculadas as médias e as variâncias das diversas distribuições ergóticas, sendo estas contrastadas com os parâmetros referentes às distribuições iniciais (1970) para cada variável.

\section{RESULTADOS}

Em todas as variáveis foi obtido um único autovalor, o que assegurou a incondicionalidade das distribuições ergóticas em relação ao vetor de distribuição inicial.

\subsection{Renda Per Capita}

A distribuição inicial ${ }^{9}$ da Renda Per Capita, gráfico 1, revela as grandes desigualdades existentes entre os municípios brasileiros em 1970. Enquanto 11,11\% das AMC possuíam apenas até $43 \%$ da média da Renda Per Capita de todas as AMC, 11,11\% possuíam entre $168 \%$ e $682 \%$ dessa média.

8 Resta, no entanto, a arbitrariedade relacionada ao número de classes utilizadas.

9 O fato de as barras pretas serem todas do mesmo tamanho decorre do processo metodológico de se dividir a amostra inicial em nove classes de mesmo tamanho. Este fato, no entanto, só ocorre quando a distribuição total do Brasil é considerada, pois as distribuições regionais refletirão a situação de suas $\mathrm{AMC}$ em relação às faixas traçadas nacionalmente. 
TABELA I - MÉDIAS E VARIÂNCIAS INICIAIS E ERGÓTICAS DA RENDA PER CAPITA

\begin{tabular}{lcccccc}
\hline & Brasil & Norte & Nordeste & Sudeste & Sul & Centro-oeste \\
\hline Média inicial & 5,0795 & 4,7063 & 2,6025 & 6,3019 & 6,2492 & 5,7848 \\
Média ergótica & 5,5557 & 2,7769 & 1,8502 & 7,4822 & 7,7534 & 6,8729 \\
Variância inicial & 6,6667 & 3,3123 & 3,0823 & 5,2186 & 2,9548 & 3,2272 \\
Variância ergótica & 8,6662 & 3,6316 & 1,1572 & 2,6329 & 1,5458 & 2,3398 \\
\hline
\end{tabular}

O Gráfico 1 mostra um padrão claro de não-convergência com a acumulação das AMC nos extremos da distribuição ergótica. Vale observar o aumento da média e da variância da distribuição ergótica em relação à distribuição inicial de 1970 (Tabela 1). ${ }^{10}$ Isso significa que caso o processo ocorrido entre 1970 e 2000 não se alterar haverá no longo prazo poucas AMC com níveis de Renda Per Capita próximos à média nacional, pois a maior parte das AMC convergirá para duas extremidades: ricas - classes 7, 8 e 9 (com Renda Per Capita entre 1,07 e 6,82 vezes maior que a da média das AMC) -, ou pobres - classes 1 e 2 (com Renda Per Capita de até $55 \%$ da média das AMC).

GRÁFICO 1 - DISTRIBUIÇÃO INICIAL E ERGÓTICA DAS AMC: RENDA PER CAPITA - BRASIL

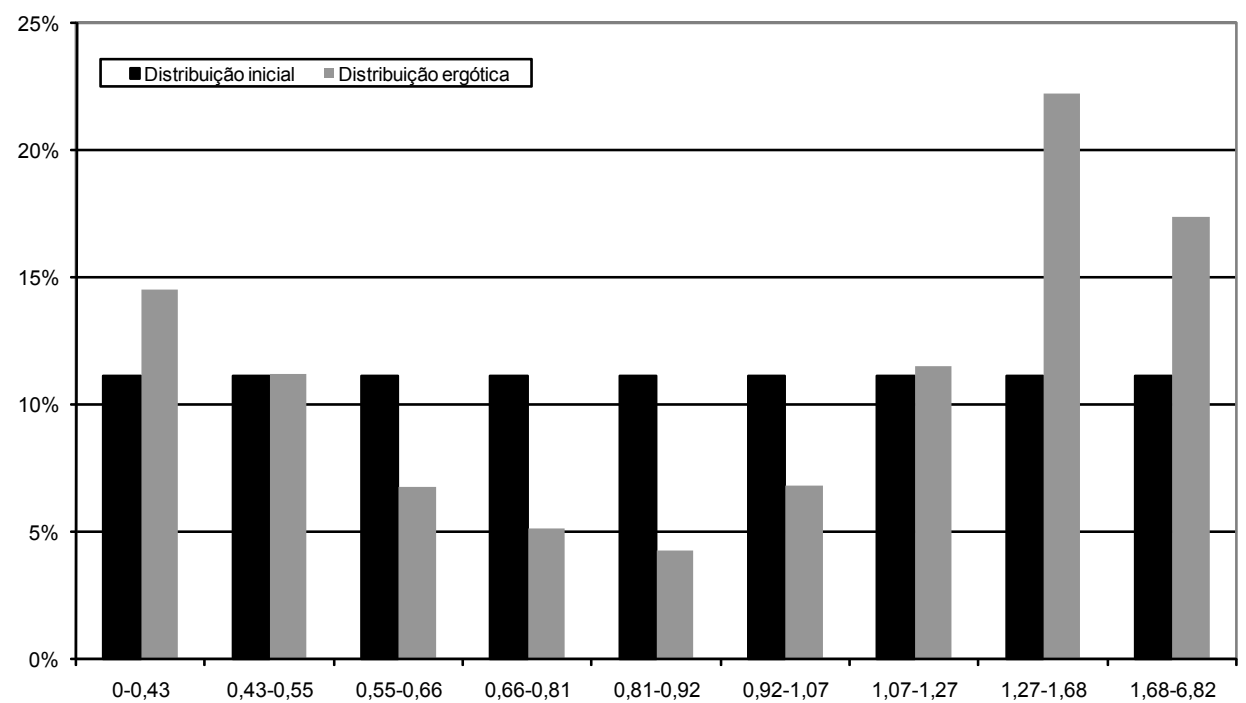

Fonte: Atlas do Desenvolvimento Humano no Brasil - Pnud/IPEA/Fundação João Pinheiro (FLP).

10 As médias iniciais e variâncias iniciais nacionais para quaisquer das variáveis analisadas são, por construção, iguais a 5,00 e 6,67, respectivamente. 
Outro resultado relevante é a existência de clubes de convergência regionais. $\mathrm{Na}$ Região Norte (Gráfico 2), pode-se observar claramente que houve aumento da desigualdade, manifestado pelo fato de a variância ergótica ser maior que a variância inicial. A queda da média relativa de 4,71 para 2,78 e a acumulação da distribuição ergótica das AMC do norte nas classes mais baixas de Renda Per Capita revelam um empobrecimento dessa região em relação ao resto do País.

\section{GRÁFICO 2 - DISTRIBUIÇÃO INICIAL E ERGÓTICA DAS AMC: RENDA PER CAPITA - NORTE}

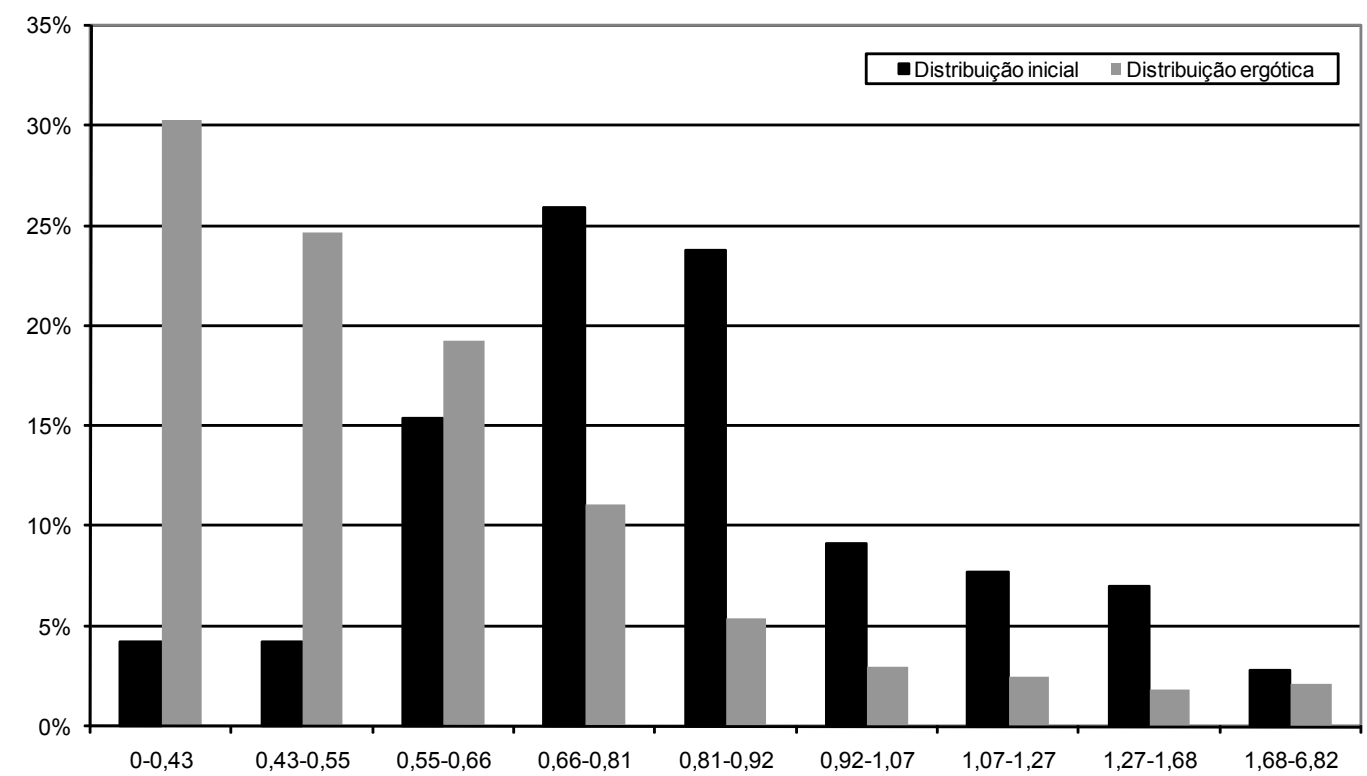

Fonte: Atlas do Desenvolvimento Humano no Brasil - Pnud/IPEA/Fundação João Pinheiro (FLP).

O problema na Região Nordeste irá agravar-se caso o processo de transição vigente nos últimos 40 anos se mantenha (Gráfico 3). O acúmulo dos municípios nas faixas mais baixas de renda, característico da distribuição inicial, sofre sensível agravamento na distribuição ergótica. Esse é o pior caso possível: uma convergência das AMC da região para as faixas mais baixas de Renda Per Capita. Numericamente, esse processo revela-se pela queda da média relativa de 2,60 para 1,85 acompanhada por uma queda expressiva na variância de 3,08 para 1,16. 


\section{GRÁFICO 3 - DISTRIBUIÇÃO INICIAL E ERGÓTICA DAS AMC: RENDA PER CAPITA - NORDESTE}

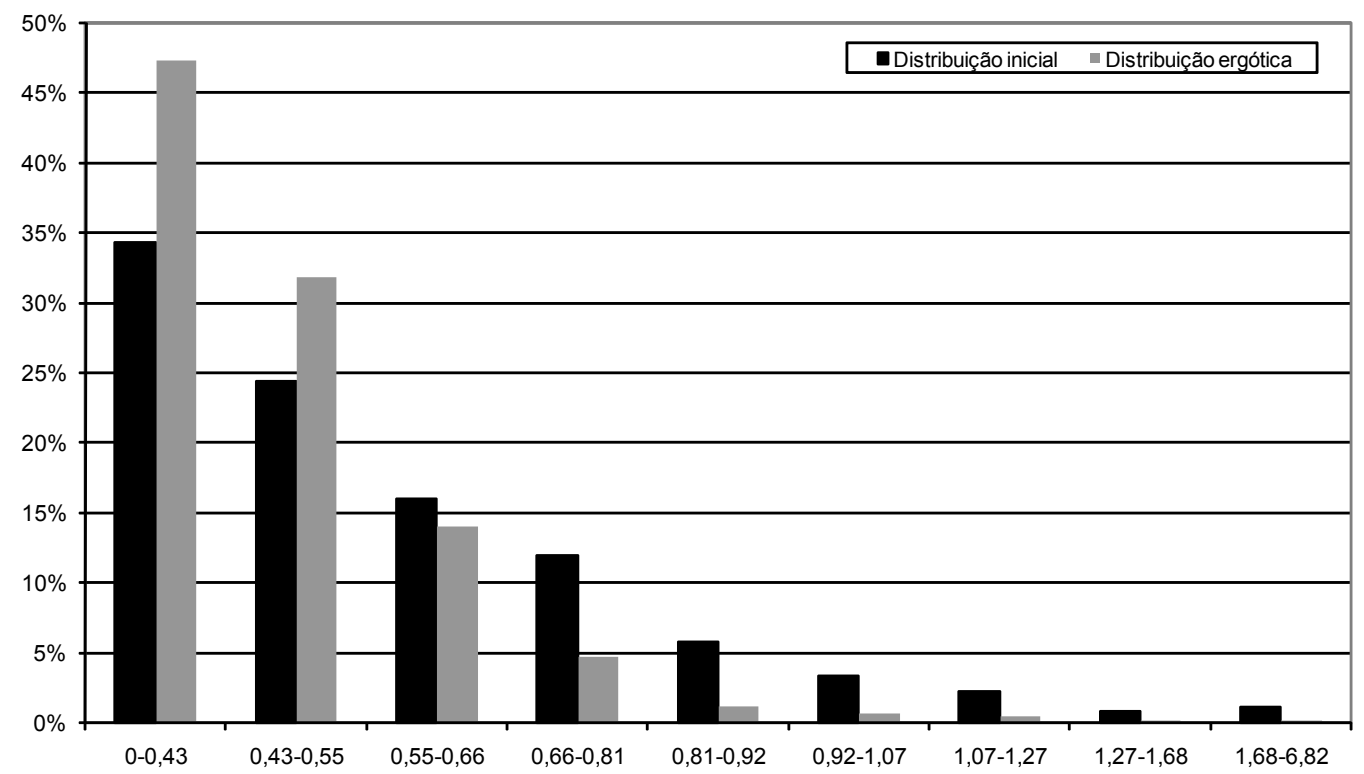

Fonte: Atlas do Desenvolvimento Humano no Brasil - Pnud/IPEA/Fundação João Pinheiro (FLP).

Como pode ser visto nos três gráficos seguintes, os casos das Regiões Sudeste, Sul e Centro-Oeste são semelhantes e o que se observa é um padrão de convergência da Renda Per Capita das AMC dessas regióes para o topo da distribuição de renda das AMC brasileiras, como também uma queda da desigualdade intrarregional de Renda Per Capita de suas AMC. Nos três casos, as médias ergóticas são mais elevadas que as médias iniciais e as variâncias ergóticas menores que as variâncias das distribuições iniciais. 
GRÁFICO 4 - DISTRIBUIÇÃO INICIAL E ERGÓTICA DAS AMC: RENDA PER CAPITA - SUDESTE

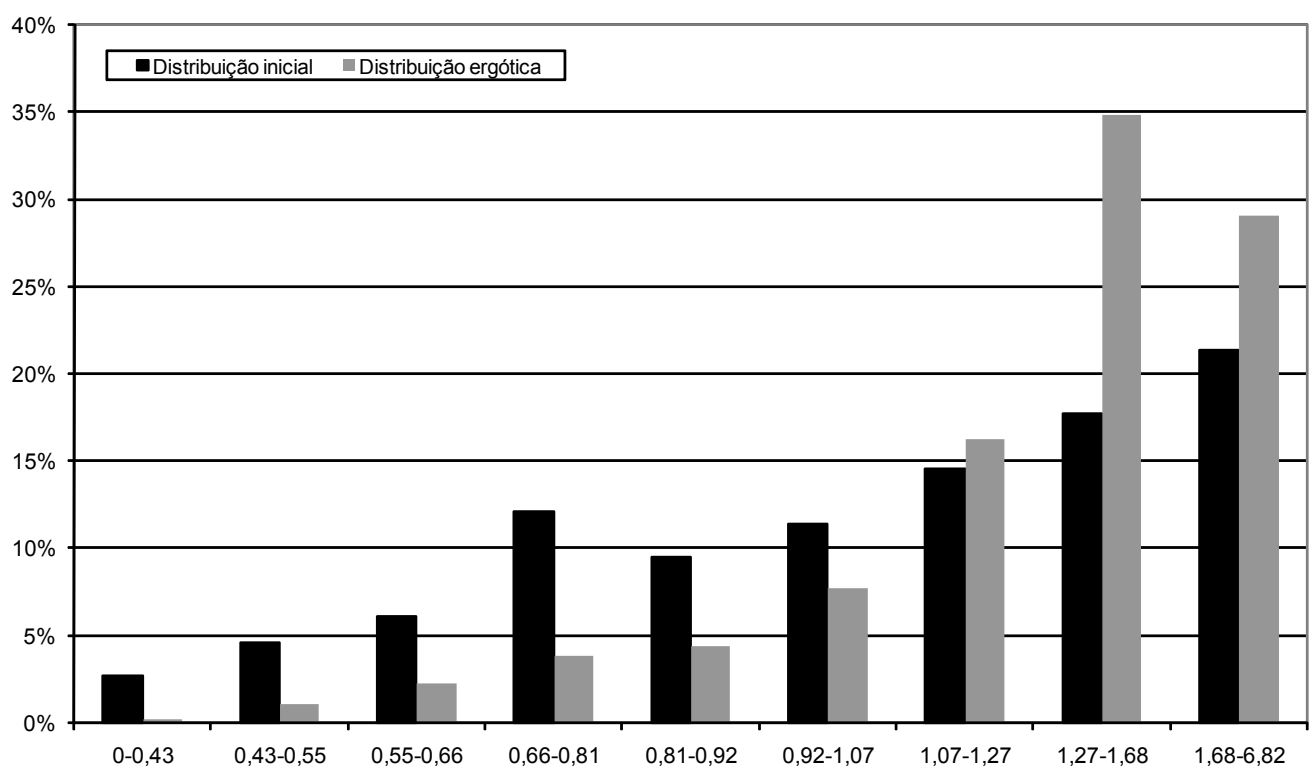

Fonte: Atlas do Desenvolvimento Humano no Brasil - Pnud/IPEA/Fundação João Pinheiro (FLP)

GRÁFICO 5 - DISTRIBUIÇÃO INICIAL E ERGÓTICA DAS AMC: RENDA PER CAPITA - SUL

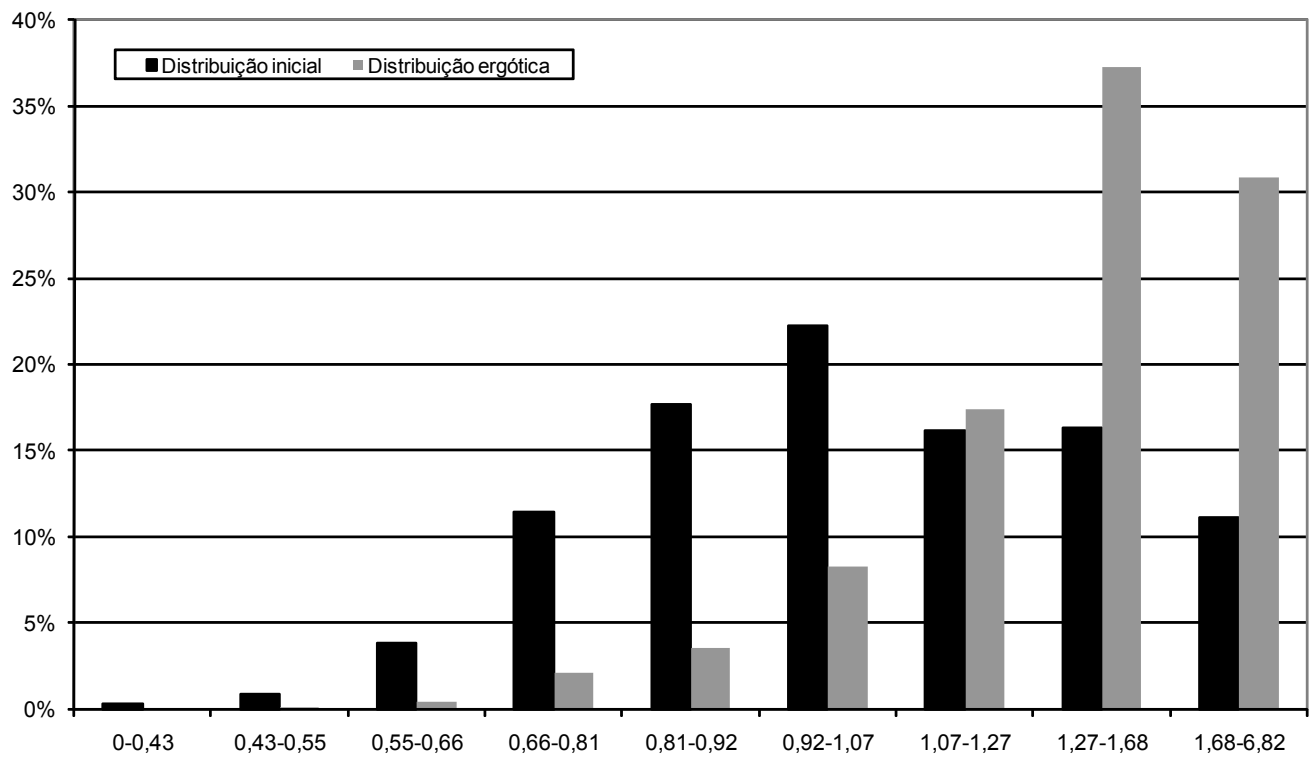

Fonte: Atlas do Desenvolvimento Humano no Brasil - Pnud/IPEA/Fundação João Pinheiro (FLP). 


\section{GRÁFICO 6 - DISTRIBUIÇÃO INICIAL E ERGÓTICA DAS AMC: RENDA PER CAPITA - CENTRO-OESTE}

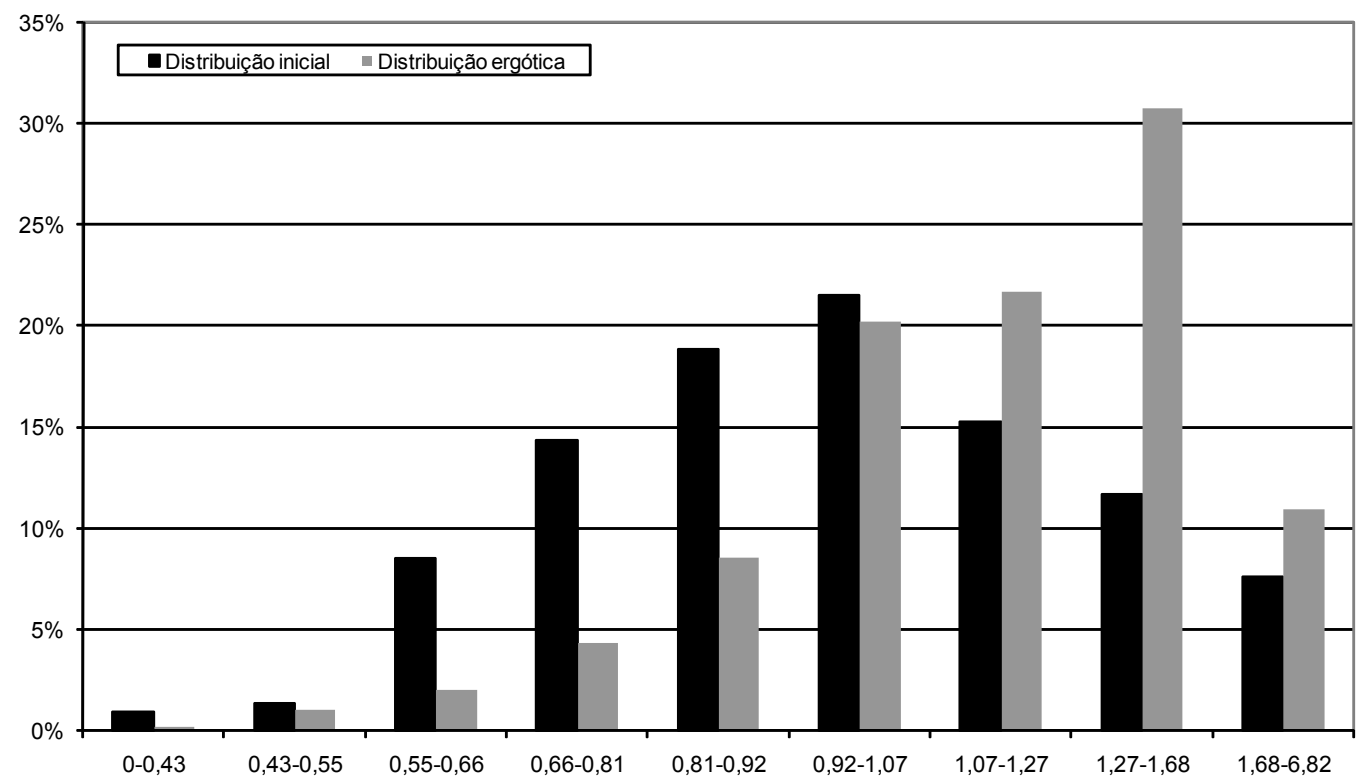

Fonte: Atlas do Desenvolvimento Humano no Brasil - Pnud/IPEA/Fundação João Pinheiro (FLP)

Portanto, esses resultados revelam que não existe uma convergência nacional da Renda Per Capita das AMC brasileiras, mas sim uma tendência de convergência por clubes, em que as AMC do Sudeste, Sul e Centro-Oeste convergem em conjunto para um padrão mais alto de Renda Per Capita, enquanto as AMC do norte e nordeste convergem conjuntamente para padrões mais baixos de Renda Per Capita.

\subsection{Taxa de Alfabetização}

A distribuição inicial da taxa de alfabetização também revela grandes desigualdades regionais e intrarregionais no Brasil. Nesta distribuição, destacavam-se as AMC do Nordeste (Gráfico 9), com as menores taxas de alfabetização, e as do Sul (Gráfico 11), com as maiores taxas. 
GRÁFICO 7 - DISTRIBUIÇÃO INICIAL E ERGÓTICA DAS AMC: TAXA DE ALFABETIZAÇÃO - BRASIL

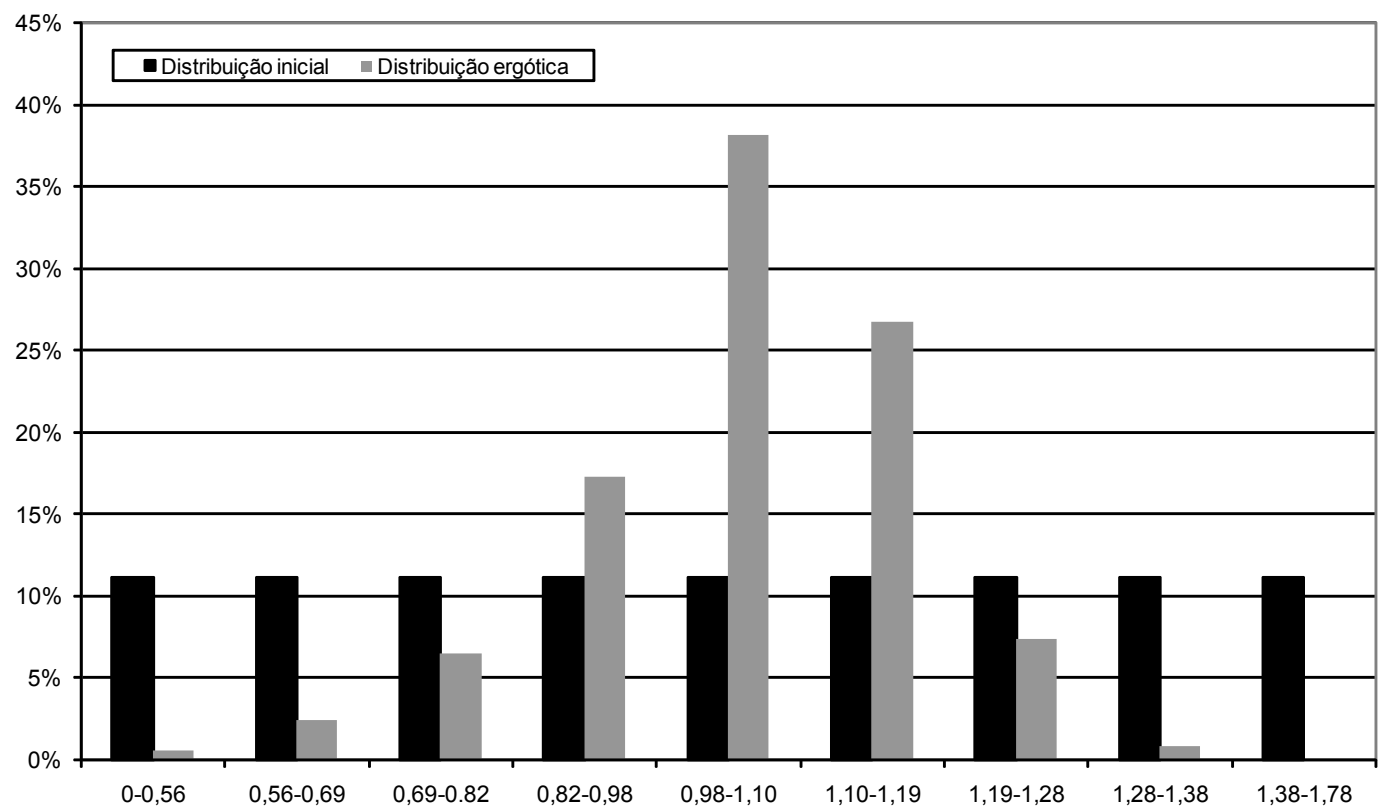

Fonte: Atlas do Desenvolvimento Humano no Brasil - Pnud/IPEA/Fundação João Pinheiro (FLP).

A distribuição ergótica revela perfis convergentes nacionais e regionais da Taxa de Alfabetização, que é confirmado pela comparação da variância ergótica $(1,40)$ em relação à variância inicial $(6,67)$ (Tabela 2 ). No âmbito nacional, observa-se uma tendência de convergência para as classes 4, 5 e 6 - faixas entre 0,82 e 1,19 da média das taxas de alfabetização das AMC.

TABELA 2 - MÉDIAS E VARIÂNCIAS INICIAIS E ERGÓTICAS DA TAXA DE ALFABETIZAÇÃO

\begin{tabular}{lcccccc}
\hline & Brasil & Norte & Nordeste & Sudeste & Sul & Centro-oeste \\
\hline Média inicial & 5,0795 & 4,4406 & 2,5493 & 6,3198 & 7,1835 & 5,4395 \\
Média ergótica & 5,0411 & 4,5094 & 3,5899 & 5,5468 & 5,6531 & 5,344 \\
Variância inicial & 6,6667 & 4,4563 & 2,0534 & 3,8264 & 3,2239 & 2,8472 \\
Variância ergótica & 1,4028 & 0,8207 & 1,0341 & 0,7587 & 0,654 & 0,4192 \\
\hline
\end{tabular}


Também ocorreu um padrão homogêneo de convergência regional. As distribuições ergóticas regionais, quando contrastadas com as distribuições iniciais, mostram que a Região Nordeste melhora relativamente, as Regiões Sudeste e Sul sofrem perdas relativas e que as Regiões Norte e Centro-Oeste tendem a manter suas médias praticamente constantes, com pequena melhora para a Região Norte e pequena queda para a Região Centro-Oeste. No entanto, as variâncias ergóticas são sempre bem menores que as variâncias iniciais, o que também revelou uma convergência intrarregional da Taxa de Alfabetização.

\section{GRÁFICO 8 - DISTRIBUIÇÃO INICIAL E ERGÓTICA DAS AMC: TAXA DE ALFABETIZAÇÃO - NORTE}

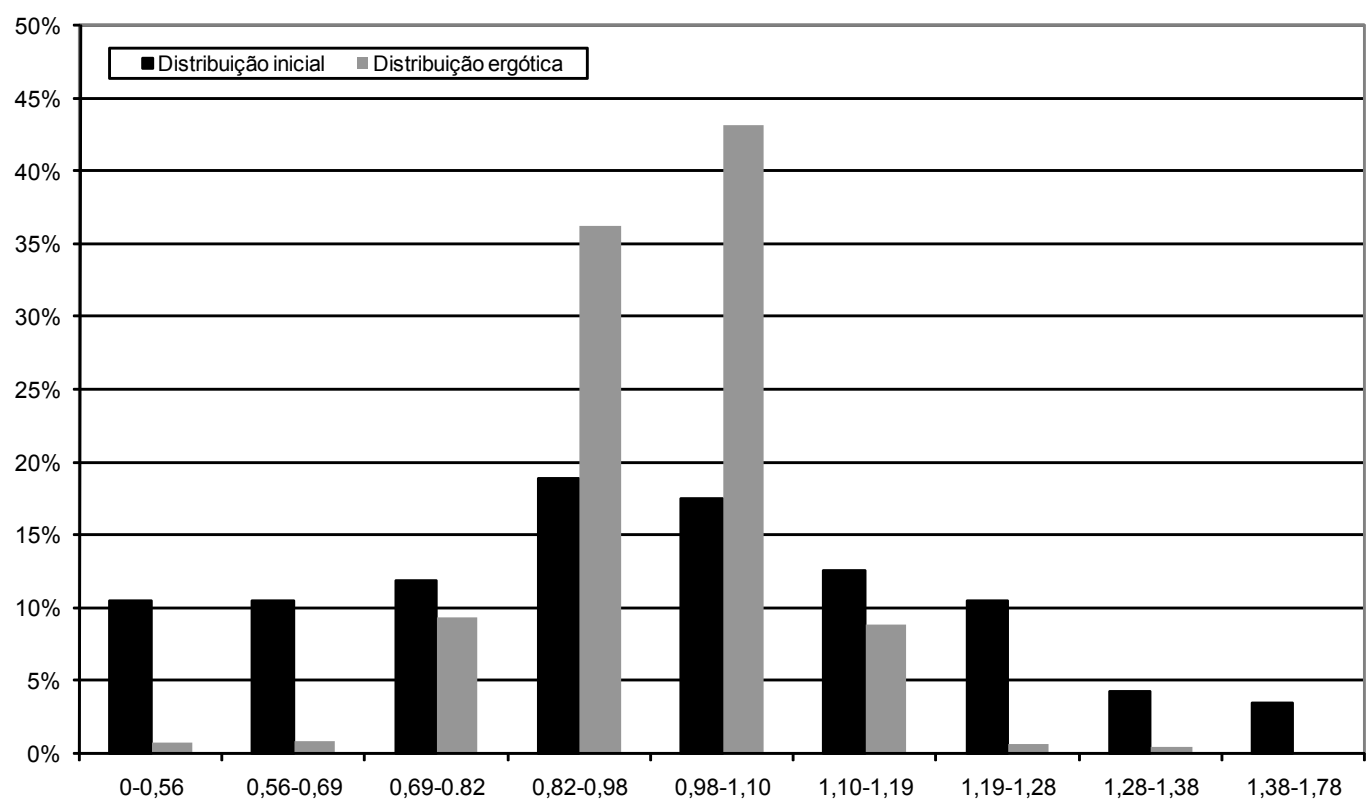

Fonte: Atlas do Desenvolvimento Humano no Brasil - Pnud/IPEA/Fundação João Pinheiro (FLP). 
GRÁFICO 9 - DISTRIBUIÇÃO INICIAL E ERGÓTICA DAS AMC: TAXA DE ALFABETIZAÇÃO - NORDESTE

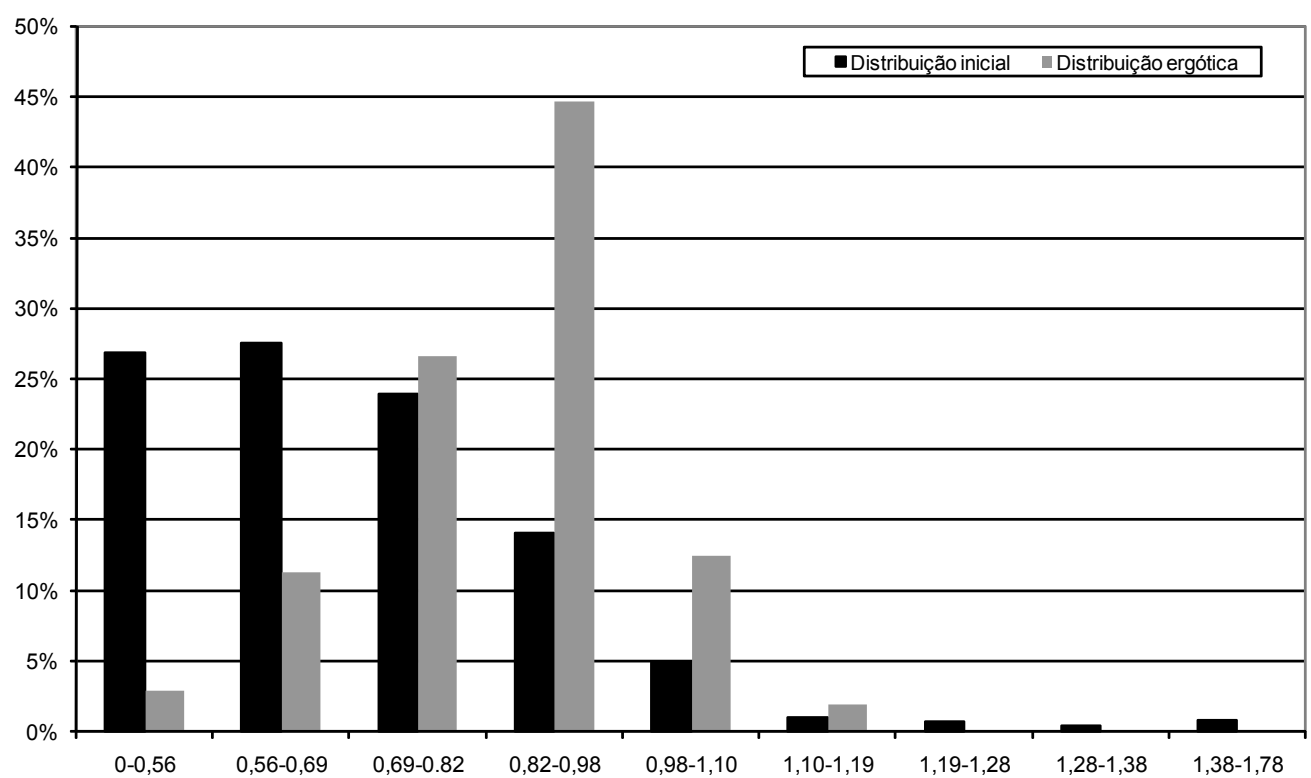

Fonte: Atlas do Desenvolvimento Humano no Brasil - Pnud/IPEA/Fundação João Pinheiro (FLP).

\section{GRÁFICO 10 - DISTRIBUIÇÃO INICIAL E ERGÓTICA DAS AMC: TAXA DE ALFABETIZAÇÃO - SUDESTE}

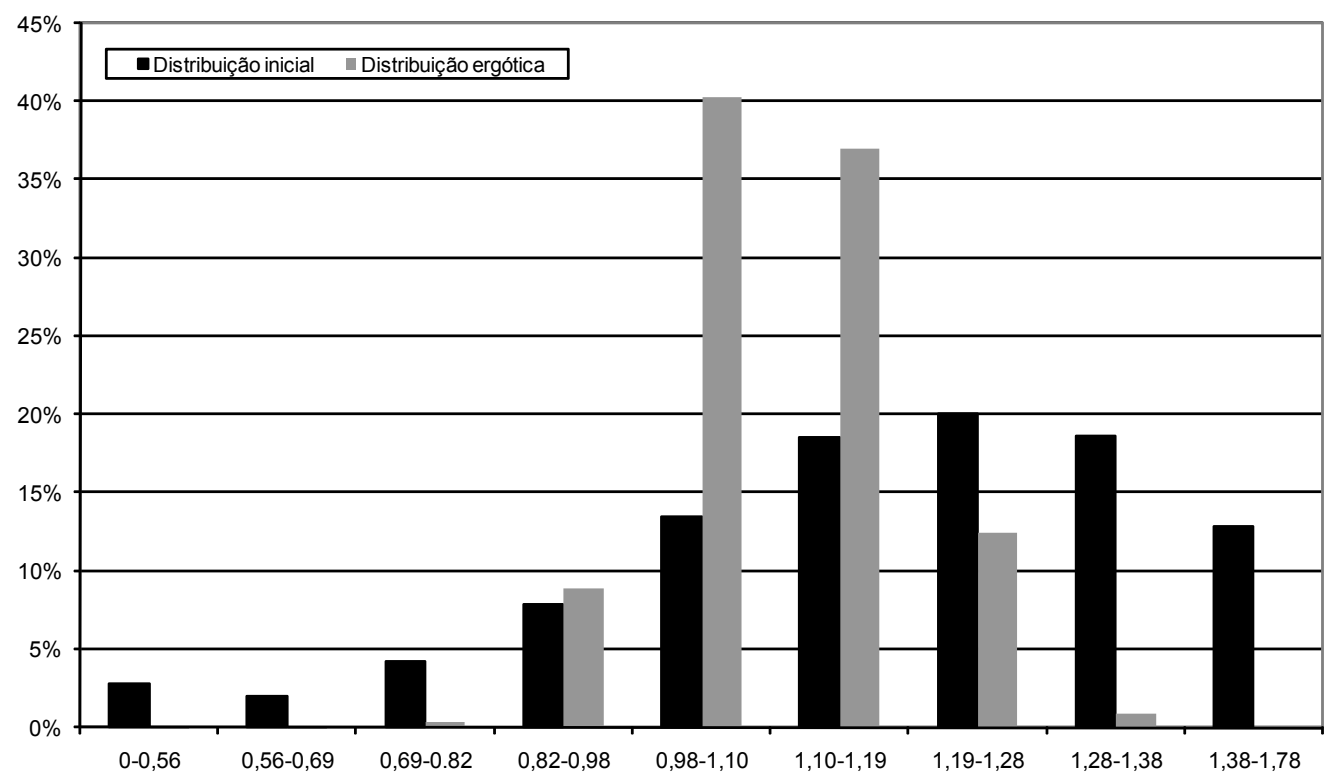

Fonte: Atlas do Desenvolvimento Humano no Brasil - Pnud/IPEA/Fundação João Pinheiro (FLP) 
GRÁFICO 11 - DISTRIBUIÇÃO INICIAL E ERGÓTICA DAS AMC: TAXA DE ALFABETIZAÇÃO - SUL

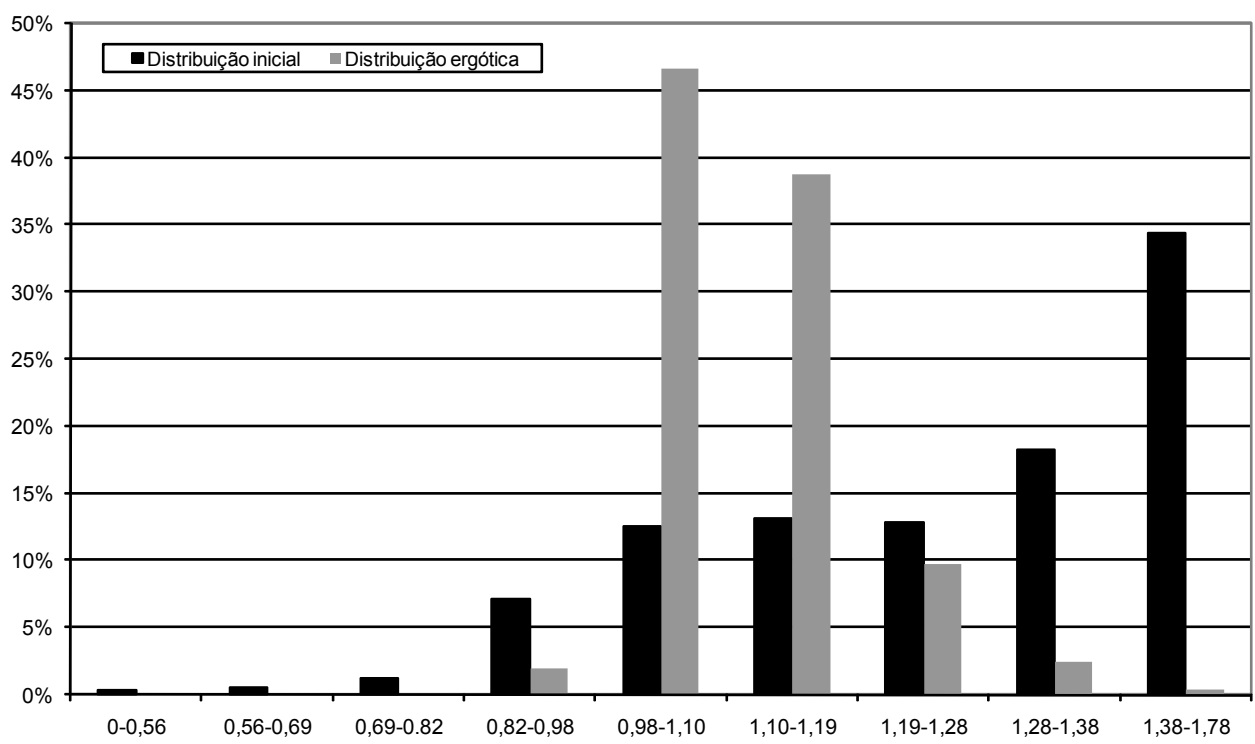

Fonte: Atlas do Desenvolvimento Humano no Brasil - Pnud/IPEA/Fundação João Pinheiro (FLP).

GRÁFICO 12 - DISTRIBUIÇÃO INICIAL E ERGÓTICA DAS AMC: TAXA DE ALFABETIZAÇAO - CENTRO-OESTE

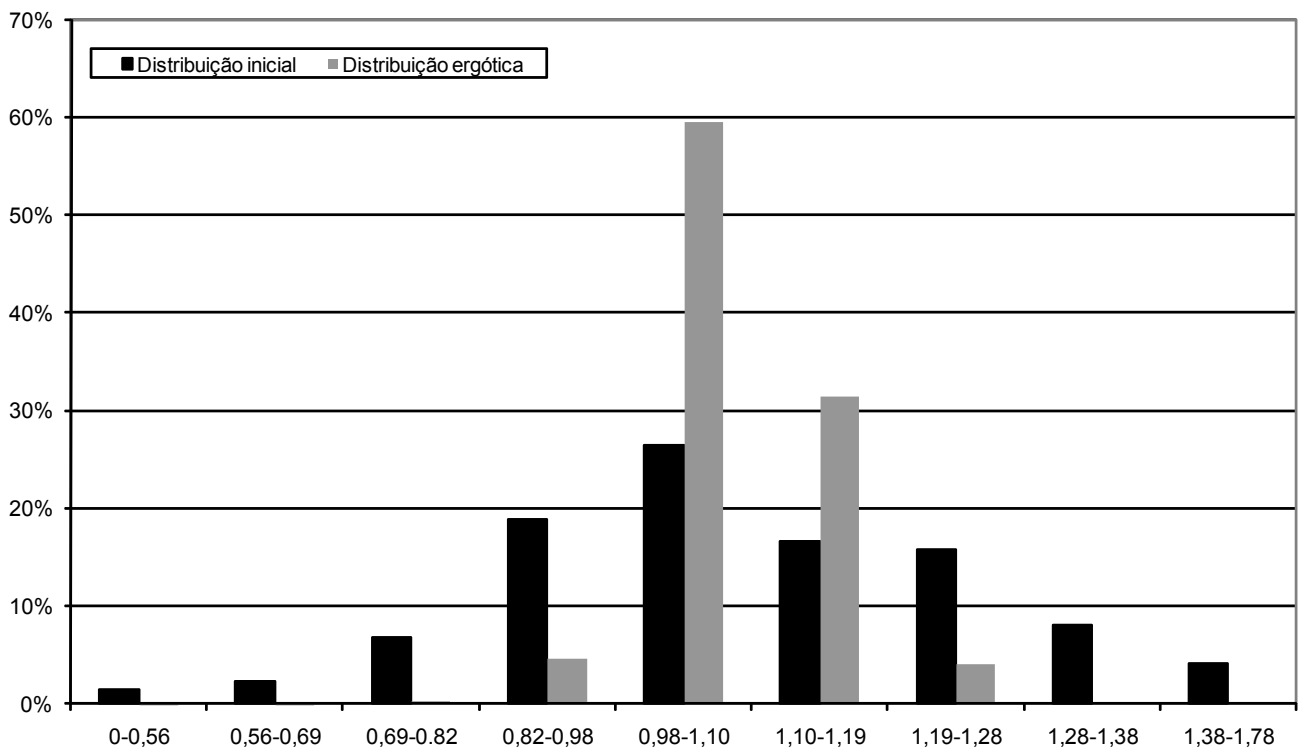

Fonte: Atlas do Desenvolvimento Humano no Brasil - Pnud/IPEA/Fundação João Pinheiro (FLP). 
Com isso, é possível afirmar que não só as regiões mais e menos favorecidas deslocam-se em direção umas às outras (convergência inter-regional), como também as AMC em cada região convergem para as mesmas classes de Taxa de Alfabetização (convergência intrarregional).

\subsection{Anos de Estudo Concluidos}

Um padrão análogo de convergência da Taxa de Alfabetização é observado na dinâmica dos Anos de Estudo Concluídos. Vemos no Gráfico 13 que a média dos Anos de Estudo Concluídos dos indivíduos em mais de 90\% das AMC brasileiras vêm convergindo para as classes 5,6 e 7 , classes que se situam entre 0,80 e 1,46 da média de Anos de Estudo das AMC brasileiras. A título de exemplo, como a média das AMC em 2000 era de 4,2 anos isso representaria valores entre 3,37 e 6,13 de Anos de Estudo Concluídos. ${ }^{11}$

\section{GRÁFICO 13 - DISTRIBUIÇÃO INICIAL E ERGÓTICA DAS AMC: ANOS DE ESTUDOS - BRASIL}

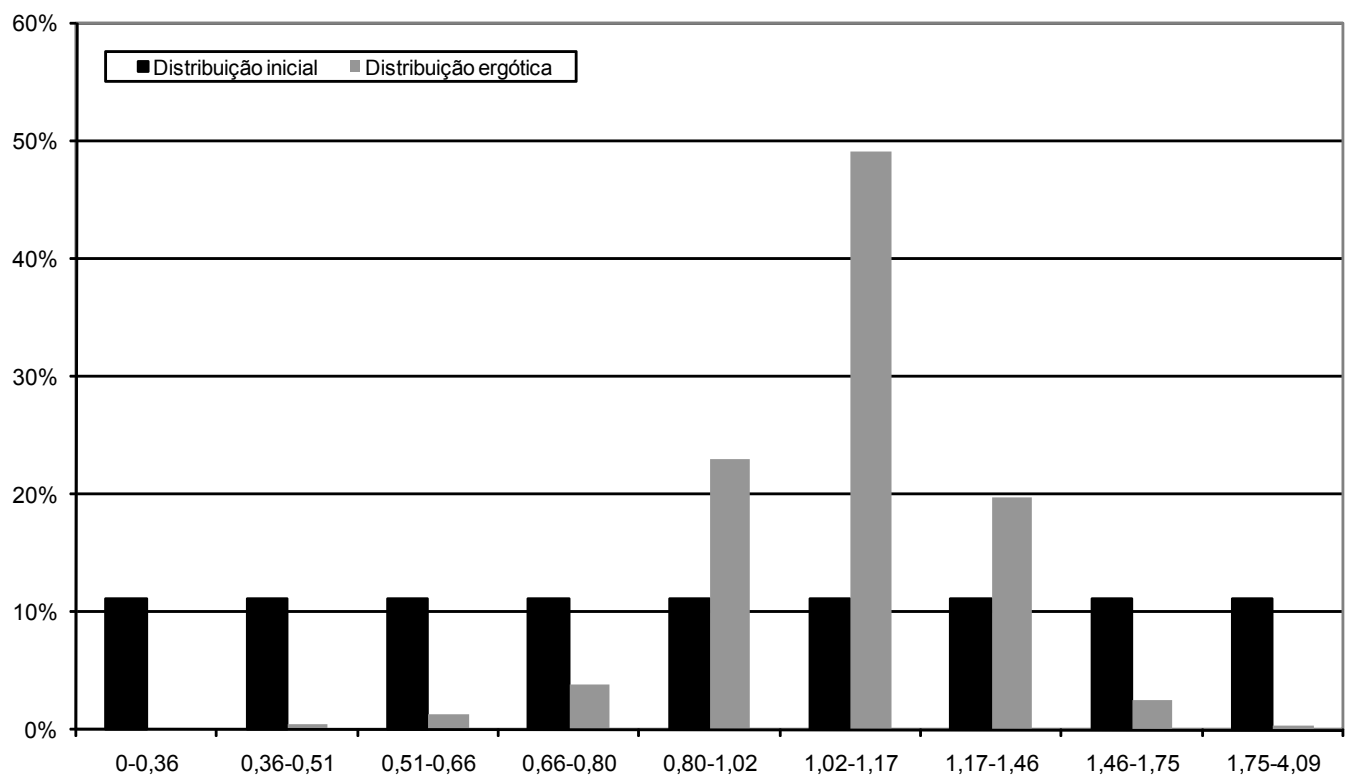

Fonte: Atlas do Desenvolvimento Humano no Brasil - Pnud/IPEA/Fundação João Pinheiro (FLP).

11 A diferença entre esse valor e a média nacional, que foi 5,9 anos, deve-se ao fato de a média de Anos de Estudo das AMC não ser ponderada pela população. 
Também vale salientar que os Anos de Estudo concluídos de quase 50\% das AMC vêm convergindo para a classe 6 , que se situa entre 1,02 e 1,16 da média das AMC brasileiras (entre 4,29 e 4,90 do valor médio das AMC em 2000).

\section{TABELA 3 - MÉDIAS E VARIÂNCIAS INICIAIS E ERGÓTICAS DOS ANOS DE ESTUDOS}

\begin{tabular}{lcccccc}
\hline & Brasil & Norte & Nordeste & Sudeste & Sul & Centro-oeste \\
\hline Média inicial & 5,0795 & 3,979 & 2,4299 & 6,2163 & 7,0943 & 4,8969 \\
Média ergótica & 5,8941 & 5,1138 & 5,2789 & 5,9903 & 6,6407 & 6,0765 \\
Variância inicial & 6,6667 & 3,9506 & 2,6226 & 4,5135 & 4,0989 & 3,5364 \\
Variância ergótica & 0,8946 & 1,4496 & 2,3289 & 0,7304 & 2,7432 & 0,5878 \\
\hline
\end{tabular}

\section{GR ÁFICO 14 - DISTRIBUIÇÃO INICIAL E ERGÓTICA DAS AMC: ANOS DE ESTUDOS - NORTE}

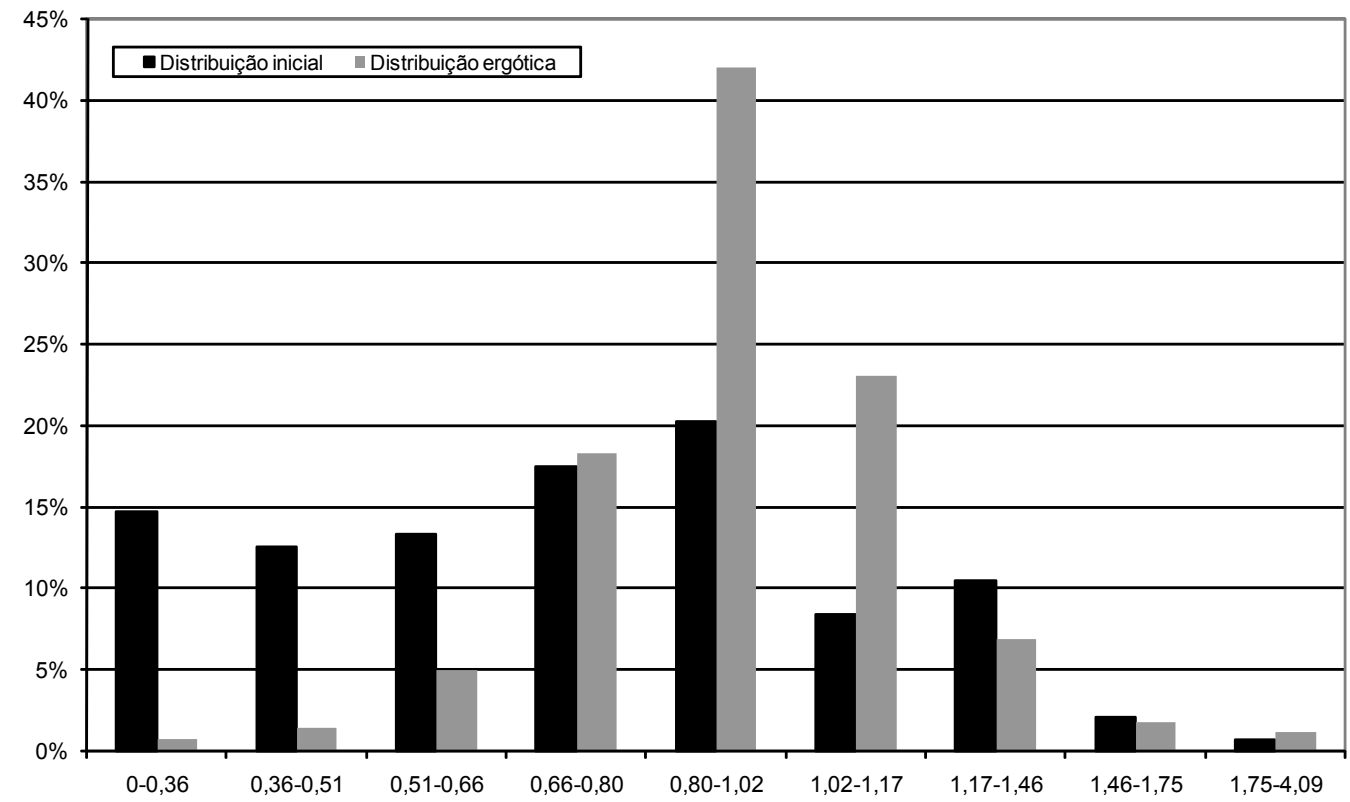

Fonte: Atlas do Desenvolvimento Humano no Brasil - Pnud/IPEA/Fundação João Pinheiro (FLP).

Melhorias acentuadas são observadas nas distribuições ergóticas da Região Norte e, em especial, da Região Nordeste, como podemos observar na queda da variância dessas regiốes (Tabela 3), e nas distribuições apresentadas nos Gráficos 14 e 15. A melhoria desta variável está provavelmente associada àquelas observadas na Taxa de Alfabetização, pois embora não se possam descartar as dificuldades existentes para que o indivíduo continue a estudar, é inegável que o analfabetismo seja uma bar- 
reira inercial poderosa, e que, uma vez superada, facilita o aumento da escolaridade e, assim, da variável "Anos de Estudo.

\section{GRÁFICO 15 - DISTRIBUIÇÃO INICIAL E ERGÓTICA DAS AMC: ANOS DE ESTUDOS - NORDESTE}

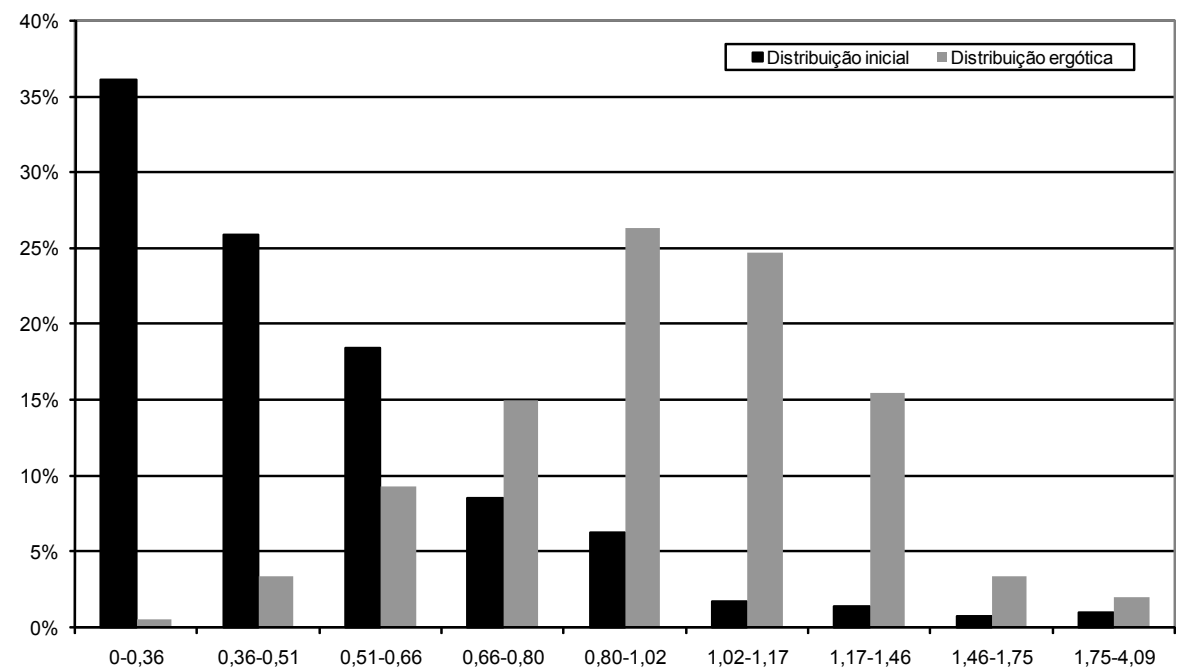

Fonte: Atlas do Desenvolvimento Humano no Brasil - Pnud/IPEA/Fundação João Pinheiro (FLP).

\section{GRÁFICO 16 - DISTRIBUIÇÃO INICIAL E ERGÓTICA DAS AMC: ANOS DE ESTUDOS - SUDESTE}

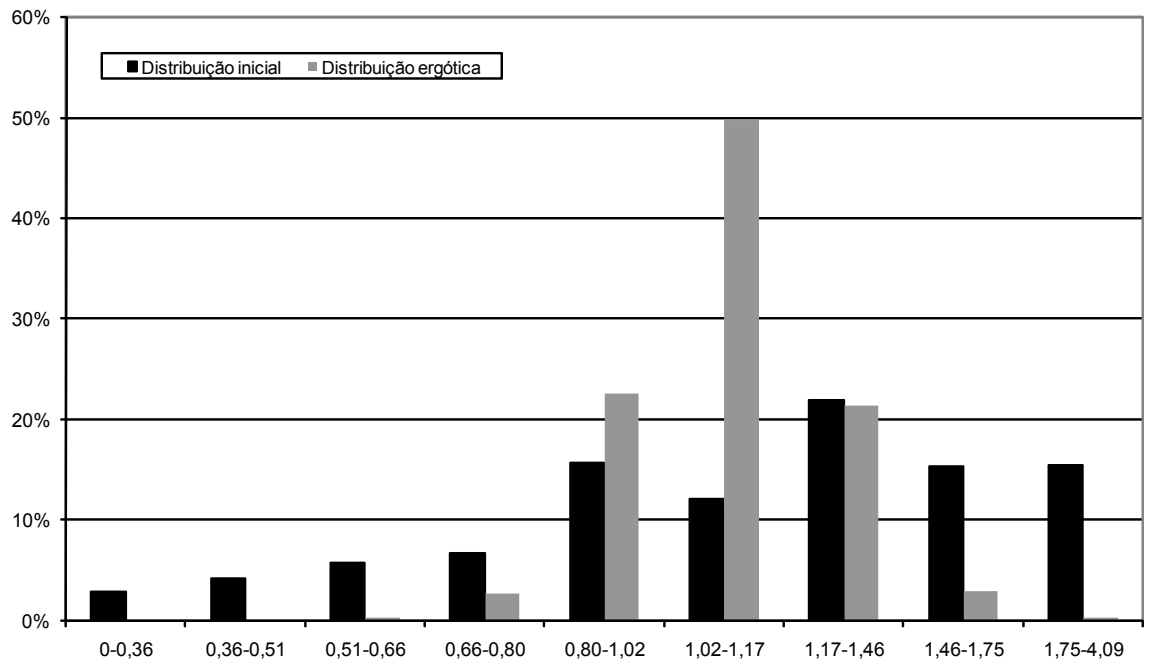

Fonte: Atlas do Desenvolvimento Humano no Brasil - Pnud/IPEA/Fundação João Pinheiro (FLP). 
GRÁFICO 17 - DISTRIBUIÇÃO INICIAL E ERGÓTICA DAS AMC: ANOS DE ESTUDOS - SUL

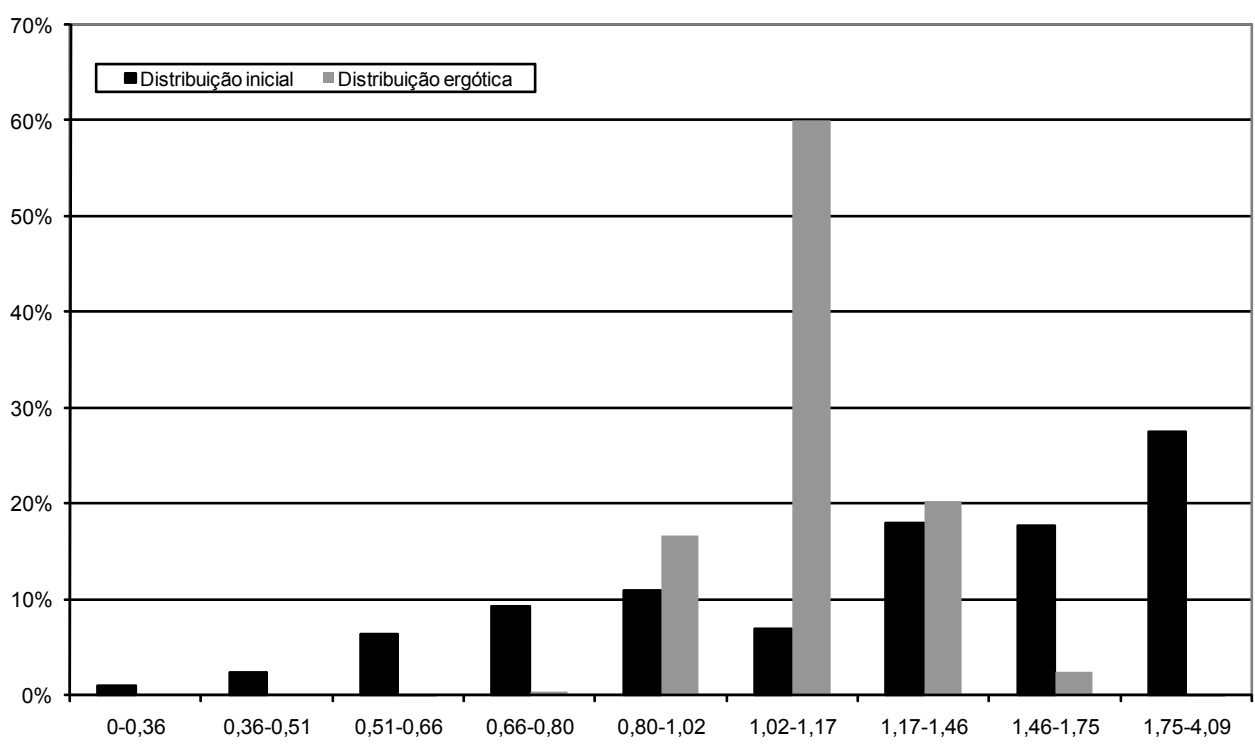

Fonte: Atlas do Desenvolvimento Humano no Brasil - Pnud/IPEA/Fundação João Pinheiro (FLP).

GRÁFICO 18 - DISTRIBUIÇÃO INICIAL E ERGÓTICA DAS AMC: ANOS DE ESTUDOS - CENTRO-OESTE

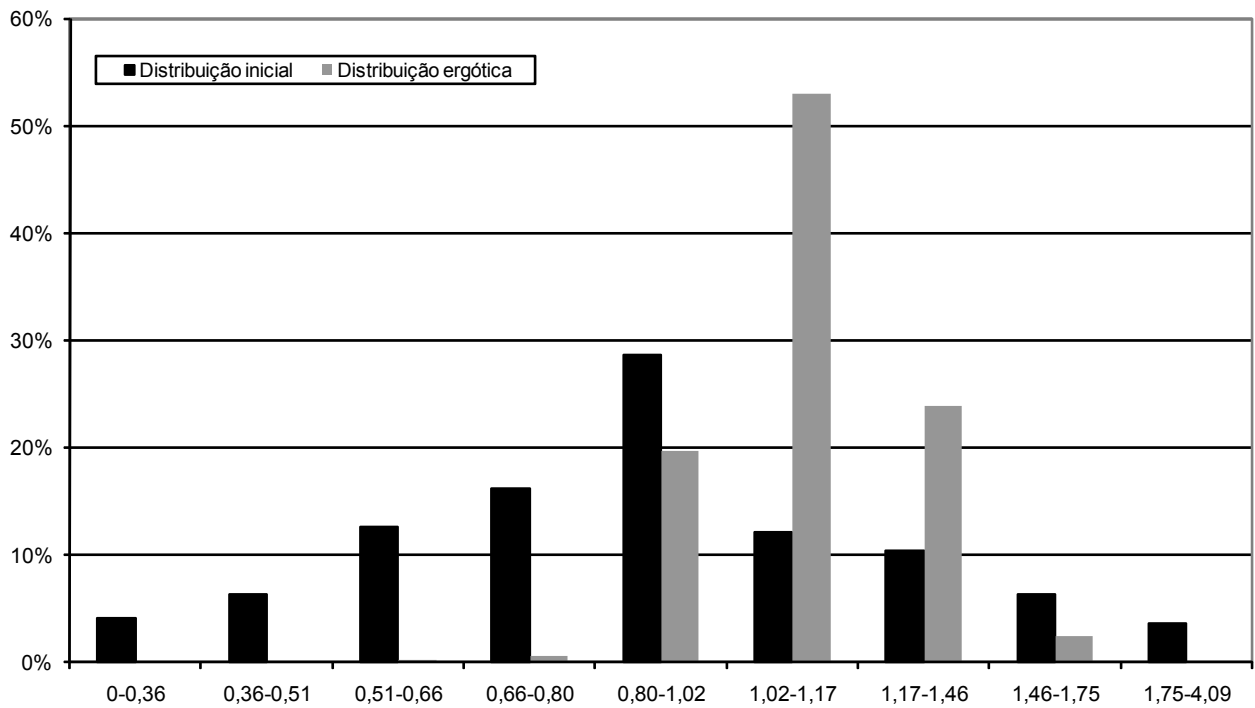

Fonte: Atlas do Desenvolvimento Humano no Brasil - Pnud/IPEA/Fundação João Pinheiro (FLP). 


\subsection{Expectativa de Vida ao Nascer}

O comportamento da variável Expectativa de Vida apresenta padrão peculiar, pois quando se observam os resultados nacionais agregados, poder-se-ia pensar que estaria ocorrendo convergência, ainda que moderada (ver Gráfico 19). Os valores da média e da variância ergóticas também parecem consubstanciar esta interpretação: embora a média ergótica não se diferencie substancialmente da inicial, sua variância é muito menor (Tabela 4).

TABELA 4 - MÉDIAS E VARIÂNCIAS INICIAIS E ERGÓTICAS DA EXPECTATIVA DE VIDA AO NASCER

\begin{tabular}{lcccccc}
\hline & Brasil & Norte & Nordeste & Sudeste & Sul & Centro-oeste \\
\hline Média inicial & 5 & 4,6014 & 3,2488 & 5,6924 & 7,0943 & 5,3946 \\
Média ergótica & 5,0699 & 4,1597 & 2,7035 & 6,5517 & 6,6407 & 5,4423 \\
Variância inicial & 6,6667 & 3,8201 & 4,7878 & 4,9953 & 4,0989 & 4,2748 \\
Variância ergótica & 5,51 & 2,4587 & 2,6617 & 2,4969 & 2,7432 & 2,1731 \\
\hline
\end{tabular}

GRÁFICO 19 - DISTRIBUIÇÃO INICIAL E ERGÓTICA DAS AMC: EXPECTATIVA DE VIDA - BRASIL

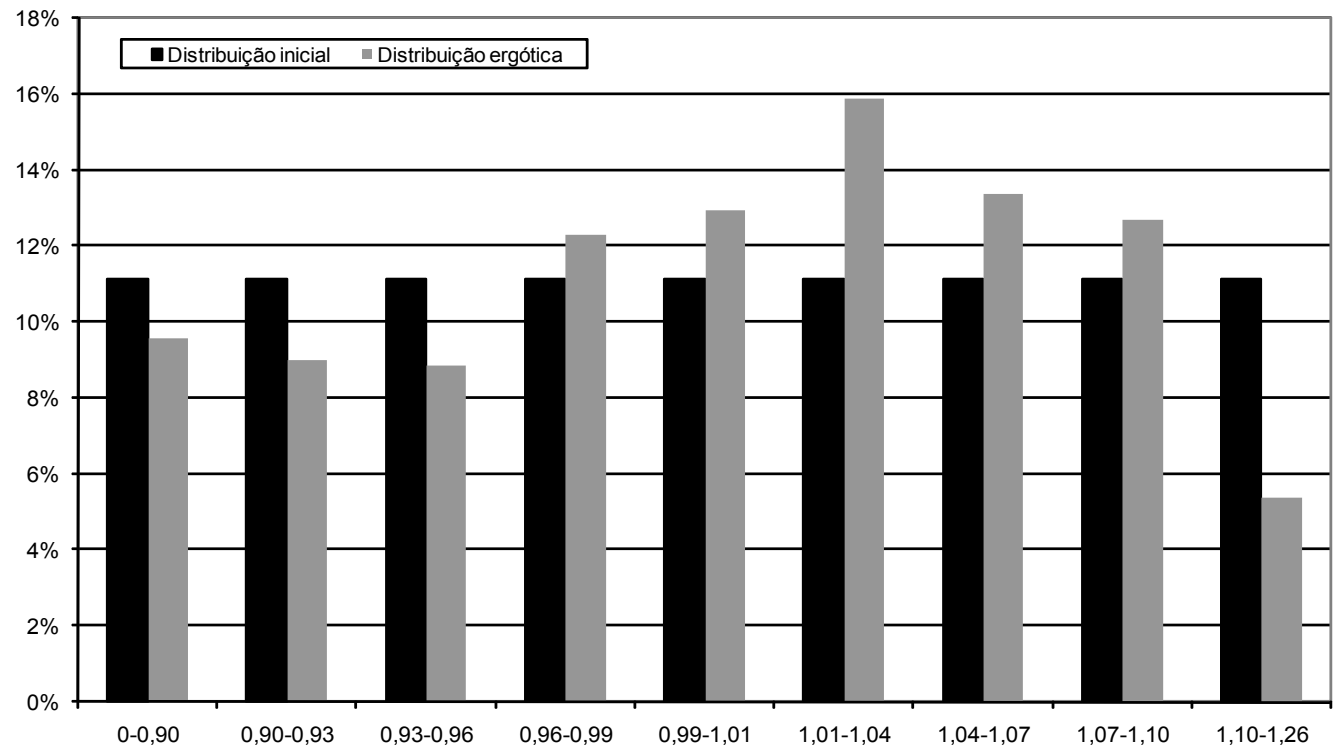

Fonte: Atlas do Desenvolvimento Humano no Brasil - Pnud/IPEA/Fundação João Pinheiro (FLP). 
Acontece que a análise sob a perspectiva regional descortina uma realidade bastante distinta daquela obtida do ponto de vista agregado. As Regióes Sul e Sudeste (Gráficos 20 e 21), embora sofram um decréscimo na frequência relativa da faixa mais alta, alcançam um incremento em suas médias, bem como diminuição em suas variâncias, indicando que a Expectativa de Vida nos municípios destas regiões está convergindo para um patamar ainda maior que o das suas respectivas médias iniciais. As distribuições ergóticas dos municípios das Regiões Sudeste e Sul são próximas, o que indica um processo de convergência entre essas duas regiões. Como a Região Sul sempre apresentou os melhores resultados, a convergência em relação ao Sudeste denota uma piora relativa do Sul.

\section{GRÁFICO 20 - DISTRIBUIÇÃO INICIAL E ERGÓTICA DAS AMC: EXPECTATIVA DE VIDA - NORTE}

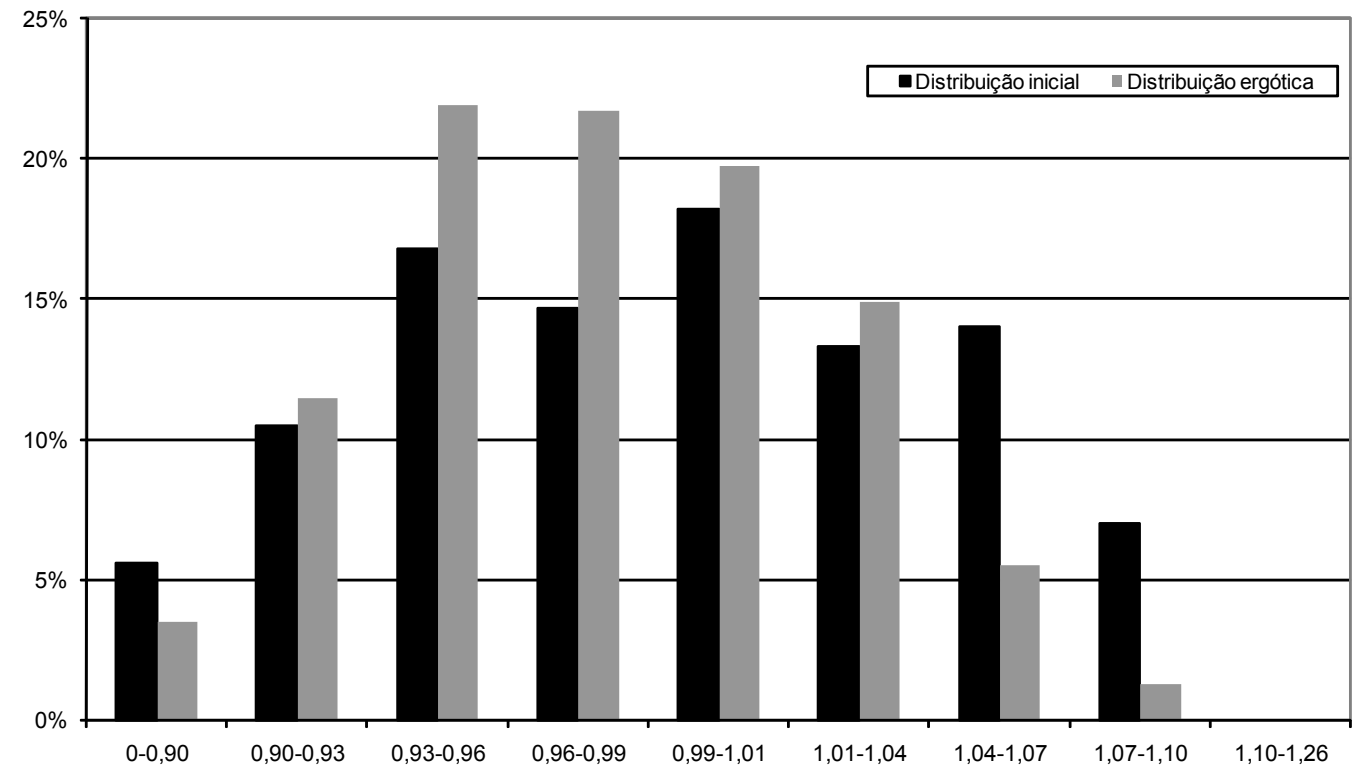

Fonte: Atlas do Desenvolvimento Humano no Brasil - Pnud/IPEA/Fundação João Pinheiro (FLP).

Já os municípios da Região Nordeste convergem para as faixas inferiores. Nessa região, ocorre uma degradação da média ergótica em relação à inicial, concomitantemente a uma diminuição da variância. ${ }^{12}$

12 Como foi dito anteriormente, o decréscimo da média não significa que a Expectativa de Vida da região está diminuindo, mas sim caindo relativamente às das outras regiões. 


\section{GRÁFICO 21 - DISTRIBUIÇÃO INICIAL E ERGÓTICA DAS AMC: EXPECTATIVA DE VIDA - NORDESTE}

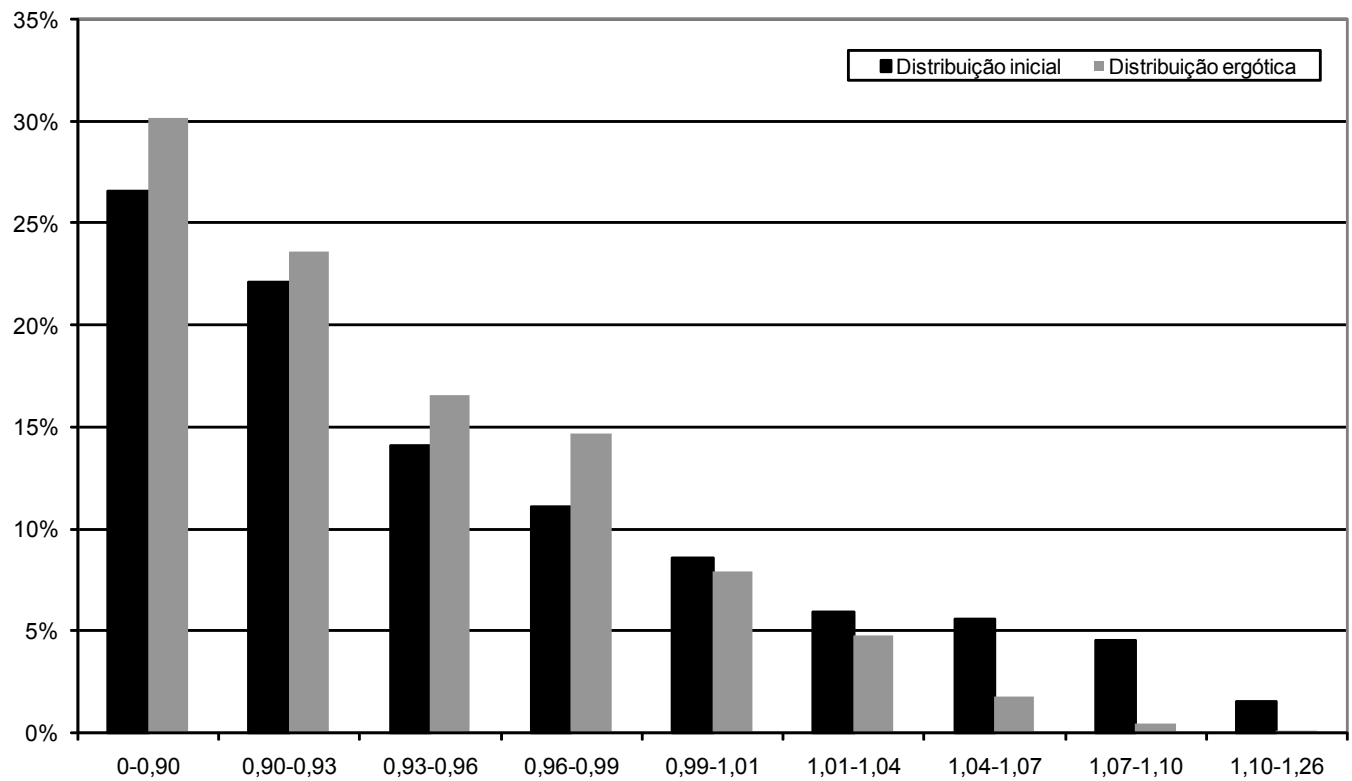

Fonte: Atlas do Desenvolvimento Humano no Brasil - Pnud/IPEA/Fundação João Pinheiro (FLP).

Situações intermediárias podem ser apreciadas nas regiões Norte e Centro-Oeste. Na primeira, existe uma pequena piora na média ergótica em relação à inicial e uma queda na variância indicando convergência intrarregional. Na segunda, ocorre um fenômeno semelhante, mas com uma distinção: a média ergótica é maior que a inicial.

Ou seja, apesar de a Expectativa de Vida nas Regióes Norte e Centro-Oeste estar convergindo em suas respectivas regiões, a média da Expectativa de Vida das AMC na Região Norte está caindo em relação à média nacional, enquanto essa média das AMC da Região Centro-Oeste está subindo. 
GRÁFICO 22 - DISTRIBUIÇÃO INICIAL E ERGÓTICA DAS AMC: EXPECTATIVA DE VIDA - SUDESTE

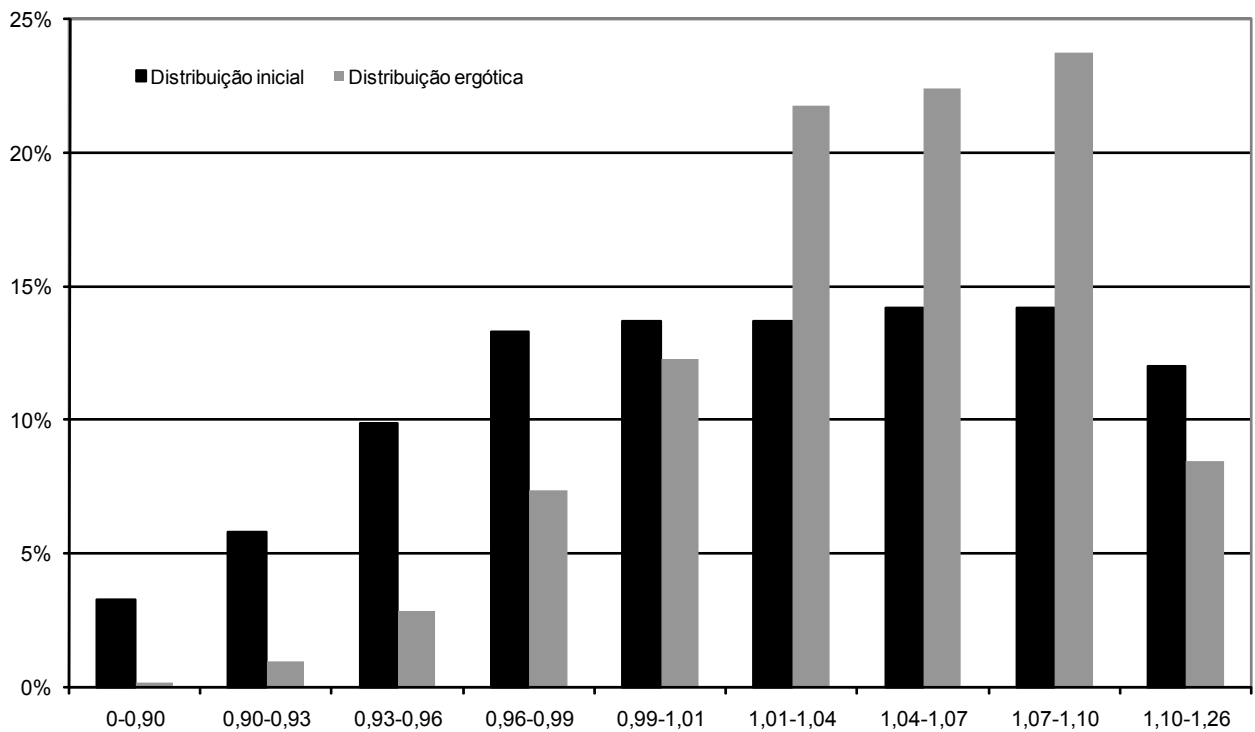

Fonte: Atlas do Desenvolvimento Humano no Brasil - Pnud/IPEA/Fundação João Pinheiro (FLP).

GRÁFICO 23 - DISTRIBUIÇÃO INICIAL E ERGÓTICA DAS AMC: EXPECTATIVA DE VIDA - SUL

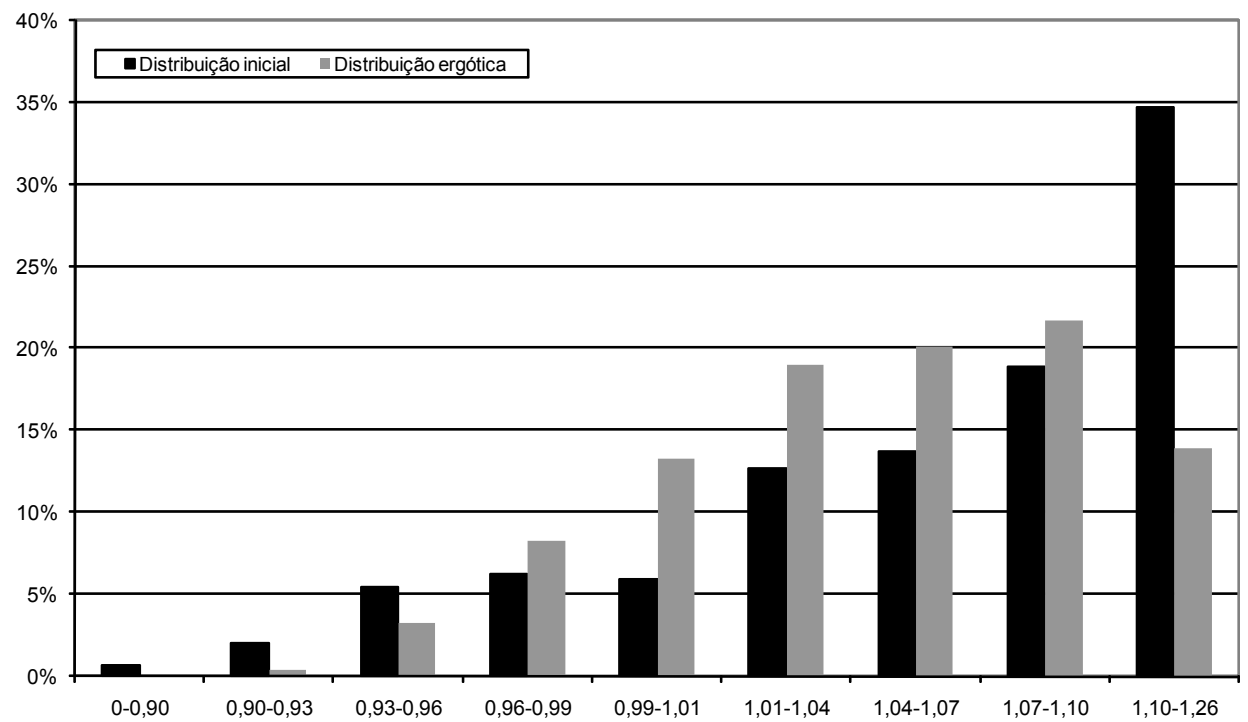

Fonte: Atlas do Desenvolvimento Humano no Brasil - Pnud/IPEA/Fundação João Pinheiro (FLP) 


\section{GRÁFICO 24 - DISTRIBUIÇÃO INICIAL E ERGÓTICA DAS AMC: EXPECTATIVA DE VIDA - CENTRO-OESTE}

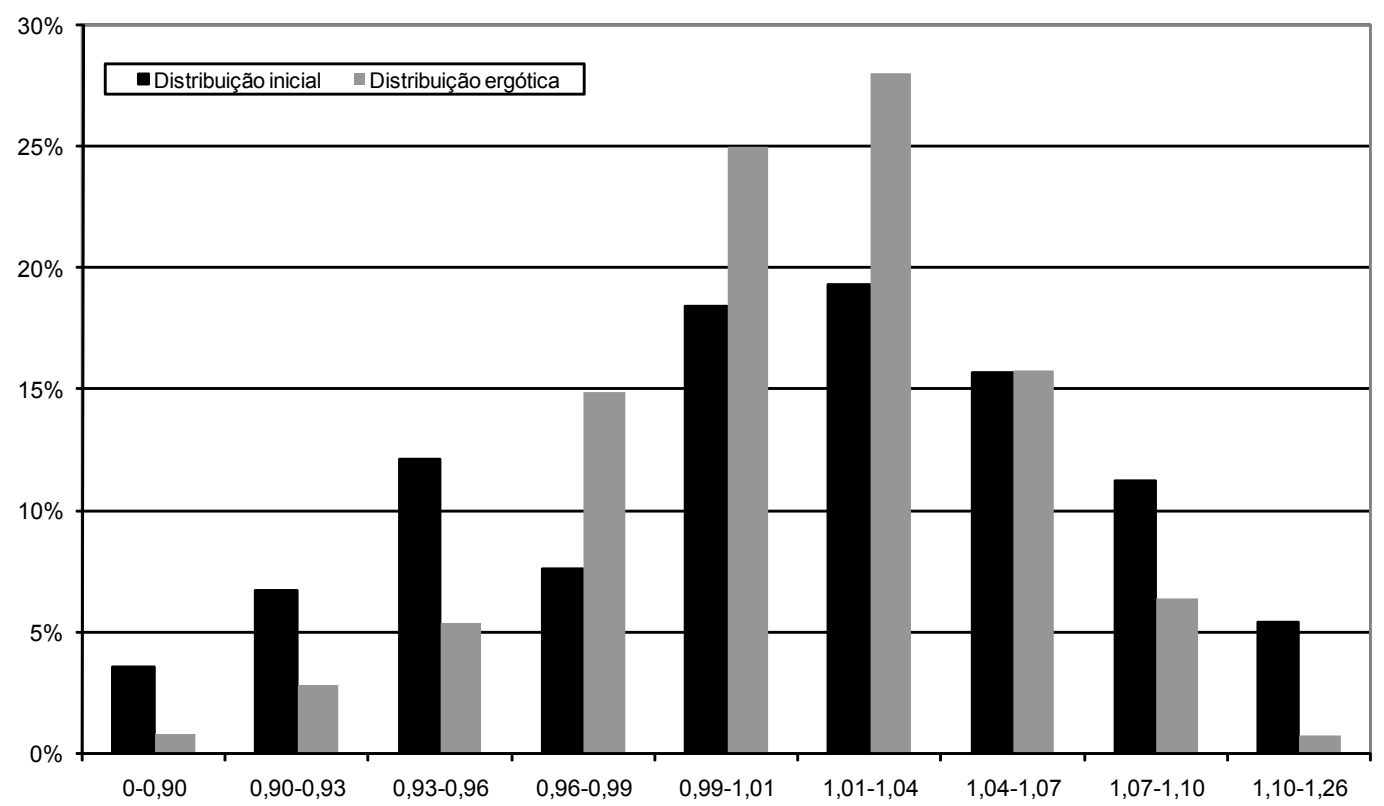

Fonte: Atlas do Desenvolvimento Humano no Brasil - Pnud/IPEA/Fundação João Pinheiro (FLP).

A apreciação dos Gráficos 20 a 25 permite então detectar, grosso modo, quatro padrões de convergência: as Regiões Sudeste e Sul estariam seguindo conjuntamente para o patamar mais elevado; a Região Centro-Oeste convergiria para um patamar imediatamente inferior, sendo seguida pela Região Norte que, por sua vez, estaria sofrendo uma queda relativa, a qual não só a manteria nos degraus mais baixos, mas pioraria sua situação relativa.

\section{CONCLUSÕES}

Este trabalho estimou matrizes de transição de Markov para revelar a dinâmica de distribuição da Renda Per Capita, da Taxa de Alfabetização, dos Anos de Estudo Concluídos e da Expectativa de Vida ao Nascer nos municípios brasileiros. As variaçóes na configuração municipal brasileira exigiram o agrupamento dos municípios em AMC.

As estimações para a Renda Per Capita indicaram grave processo de divergência no Brasil caracterizado pela formação de dois clubes de AMC: enquanto a maior parte 
das AMC das Regiões Sul, Centro-Oeste e Sudeste estão se concentrando em uma faixa entre 1,27 e 1,68 vezes maior que a média das AMC brasileiras, as AMC das Regióes Norte e Nordeste caminham para faixas entre 0 e 0,55 dessa média.

Esse resultado revela que se a dinâmica ocorrida entre 1970 e 2000 não se alterar, haverá uma distribuição de longo prazo em que a maioria das AMC do Norte e do Nordeste terá aproximadamente um terço da Renda Per Capita das AMC do CentroOeste, do Sul e do Sudeste. No entanto, é importante apontar a ocorrência de fatores inerentes ao período 1970 e 2000, como a estabilização financeira e a abertura econômica, que podem ter afetado essa distribuição e que possíveis mudanças institucionais futuras, como a implementação de novas políticas regionais, mudanças nos custos à mobilidade do capital e da mão de obra, também podem afetar a dinâmica futura da distribuição da Renda Per Capita.

Ao contrário da Renda Per Capita, no caso das variáveis ligadas à educação - Taxa de Alfabetização e Anos de Estudo Concluídos -, existe um padrão nítido de convergência entre as AMC das diversas regióes brasileiras, apesar de persistirem pequenas diferenças regionais. Esse padrão de convergência pode ser explicado pelos enormes gastos públicos federais em educação.

Um dos empecilhos para a avaliação das diferenças educacionais no território brasileiro refere-se à obtenção de um indicador qualitativo de educação. É razoável supor que existam diferenças territoriais significativas de qualidade educacional e que outros fatores também afetem o nível de aprendizagem dos alunos e o consequente processo de acúmulo de capital humano, tais como: escolaridade dos pais, condições de transporte, habitação e saneamento, violência, existência de um mercado de trabalho local que incentive o investimento individual em educação e expectativa de vida ao nascer.

Quanto à variável Expectativa de Vida ao Nascer, foi constatada uma tendência muito suave de convergência, revelada pela concentração das AMC nas classes centrais - entre 0,96 e 1,1 vezes a média de Expectativa de Vida das AMC brasileiras - e por uma variância ergótica menor que a variância inicial. No entanto, a observação desagregada por regiões revela um processo de convergência em clubes: 1) as AMC do Sul e Sudeste formam o primeiro clube, que converge para maiores valores de Expectativa de Vida - entre 1,01 e 1,1 vezes a média das AMC brasileiras; 2 ) as AMC do Norte e Centro-Oeste estão convergindo para uma posição intermediária - entre 0,93 e 1,07 vezes a média das AMC brasileiras; 3 ) as AMC do Nordeste caminham para valores relativamente mais baixos: entre 0 e 0,93 vezes a média nacional. 
Esse comportamento provavelmente foi orientado por dois fatores: 1) grandes transferências compulsórias aos municípios para a saúde somadas ao transbordamento de novas tecnologias de prevenção e combate a doenças desenvolvidas em países e em regiões mais ricas, que também elevaram enormemente a Expectativa de Vida de toda a população brasileira; 2) o processo de divergência da Renda Per Capita dos municípios brasileiros, que desestimula a convergência absoluta da Expectativa de Vida entre esses municípios.

\section{REFERENCIAS}

AZZONI, C. R. Economic growth and regional income inequality in Brazil. The Annals of Regional Science, Alemanha, v. 35, n. 1, p. 133-152, Feb. 2001.

; MENEZES FILHO, N.; MENEZES, T. A.; SILVEIRA NETO, R. M. Geography and income growth accross Brazilian states: evidence from cohort data. Journal of Regional Science, 2004.

BARRO, R. Economic growth in a cross-section of countries. Quarterly Journal of Economics, v. 106. p. 7-43, maio, 1991.

; SALA-I-MARTIN, X. Convergence. Journal of Political Economy, v. 100, n. 2, p. 223-25l, 1992.

. Convergence across states and regions. Brookings Papers on Economic Activity, n. 1, p. 107-158, 1991.

BECKER, G.; T. PHILIPSON, SOARES, R. The quantity and quality of life and the evolution of world inequality. National Burean of Economic Research. Cambridge, MA, June 2003.

CASS, D. Optimum growth in an aggregative model of capital accumulation. Review of Economic Studies, v. 32, n. 91, p. 233-240, July 1965.

FERREIRA, A. H. Concentração regional e dispersão das rendas per capita estaduais: um comentário. Belo Horizonte: Cedeplar/UFMG, 1998.(Texto para Discussão, n. 121)

; DINIZ, C. C. Convergência entre rendas per capita estaduais no Brasil. Revista de Economia Política, v. 15, n. 4, p. 38-56, 1995.

FERREIRA, P. C.; PESSOA, S. The costs of education, longevity and the poverty of nations. Ensaio Econômico de 2003, EPGE/RJ, 27 ago. 2003.

FRIEDMAN, M. Do old fallacies ever die? Journal of Economic Literature, v. 30, p. 2199-2132, 1992.

GONDIM, J. L. B.; BARRETO, Flávio A.; CARVALHO, José R.. Condicionantes de clubes de convergência no Brasil. Estudos Econômicos, São Paulo, v. 37, n. 1, p. 71-100, jan.-mar. 2007. 
HAZAN, M.; ZOABI, H. Longevity, fertility and economic growth. The Hebrew University of Jerusalem, Sept. 2003.

KOOPMANS, T. C. On the concept of optimal economic growth. Pontificacia Academia Scientiarum. The econometric approach to development planning. Amsterdam: North-Holland, p. 225-287, 1965.

KROTH, D. C.; DIAS, J. A contribuição do crédito bancário e do capital humano no crescimento econômico dos municípios brasileiros: uma avaliação em painéis de dados dinâmicos. Anais do XXXIV Encontro Nacional de Economia da ANPEC - Associação Nacional dos Centros de Pós Graduação em Economia, 2006.

LAURINI, M. P.; ANDRADE, E. Clubes de convergência de renda para os municípios brasileiros: uma análise não-paramétrica. Macroeconomia Aplicada, ANPEC, 21 jul. 2003.

MINCER, J. Schooling, experience, and earning. National Bureaus of Economic Research. Columbia University Press, 1974.

MOSSI, M. et al. Growth dynamics and space in Brazil. International Regional Science Review, London, v. 26, n. 3, 2003.

PONTUAL, E.; PORTO JR. S. Crescimento e convergência: uma análise empírica para a região sul. Anais do Encontro de Economia da Região Sul, 2000.

QUAH, D. Galton's fallacy and the tests of the convergence hypothesis. Scandinavian Journal of Economics, v. 95, p. 427-443, 1993 a.

. Empirical cross-section dynamics in economic growth. European Economic Review, North-Holland, n. 37, p. 426-434, 1993 b.

RAMSEY, F. P. A mathematical theory of saving. Economic Journal, v. 38, n. 152, p. 543-559, Dec.1928.

SOARES, Rodrigo R. Health and the evolution of welfare across Brazilian municipalities. NBER Working Paper 13087, Cambridge, May 2007.

SOLOW, R. M. A contribution to the theory of economic growth. Quarterly Journal of Economics, v. 70, n. 1, p. 65-94, Feb. 1956.

SWAN, T. W. Economic growth and capital accumulation. Economic Record, v. 2, n. 63, p. 334-361, Nov. 1956.

VREYER, P.; SPIELVOGEL, G. Spatial externalities between Brazilian municípios and their neighbours. Ibero-America Institute for Economic Research Discussion Papers, Georg-August-Universität Göttingen, n. 123, Oct. 2005. 